\title{
MACRO- AND MICROMORPHOLOGY OF THE LEAF, STEM AND INFLORESCENCE OF CASSIA BICAPSULARIS L. CULTIVATED IN EGYPT
}

M. A. Makboul, M. A. Abd El-Hafiz, E. K. Desoky and I. A. Mahmoud*

Department of Pharmacognosy, Faculty of Pharmacy, Assiut University, Assiut, Egypt

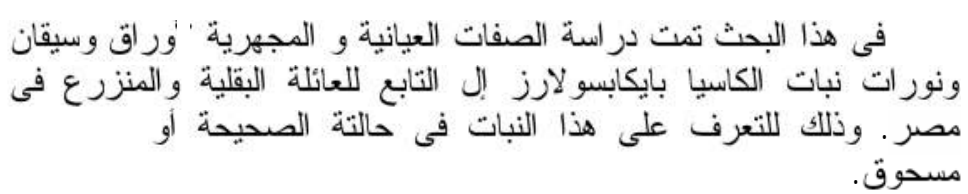

The macro- and micromorphology of the leaf, stem and inflorescence of Cassia bicapsularis L. family Fabaceae, cultivated in Egypt have been studied in order to determine the diagnostic features which can help in the identification of the plant in both entire and powdered forms.

\section{INTRODUCTION}

Cassia bicapsularis L. (Family Fabaceae) is a glabrous shrub attaining 3-4 meters in height. It is common in tropical America and it is cultivated for ornament in warm countries. ${ }^{1-3}$

The plant has many old synonymous as winter cassia, butterfly bush, christmas senna, yellow candle wood and rambling cassia, also it is known as Senna bicapsularis, Adipera bicapsularis and Cassia emarginata. ${ }^{4-8}$
The genus Cassia has wide uses in folk medicine as laxative, to relief toothache, as a remedy for ophthalmia, venereal diseases, cough and as anthelmintic for ringworms. ${ }^{9-11}$ From the genus Cassia anthraquinones, alkaloids and flavonoids have been isolated and studied. ${ }^{12-14}$ Now we are investigating the phytochemistry of Cassia bicapsularis $\mathrm{L}$.

In continuation of our work we report here the macro- and micromorphology of the leaf, stem and inflorescence of Cassia bicapsularis L. to reveal the

Received in 3/8/2006 \& Accepted in 3/12/2006

* Corresponding author. 
diagnostic features by which the plant can be identified in the entire and powdered forms.

\section{Habitat}

Cassia bicapsularis L. (Fig. 1A) is an evergreen shrub or a small tree attaining 3-4 meters in height. Leaves (Figs. 1B\&2) are alternate, compound, paripinnate of 3 pairs (the lowest pair is the smaller) of obovateoblong leaflets, the lowest pair with a gland at the base. Flowers (Fig. 1C) are bright yellow, arranged in racemes. Pods (Fig. 1D) are cylindrical, long legumes. The flowering seasons are from February to April and from July to September but the fruiting seasons in May and October.

\section{PLANT MATERIAL}

Cassia bicapsularis $\mathrm{L}$ is cultivated in the experimental station of Faculty of Pharmacy, Assiut University, Assiut, Egypt. The plant material was collected in the period from July to September 2001 during the flowering stage of the plant. The plant was kindly identified by Trease Demian, director of Orman botanical garden, Giza, Egypt.

The material used for the botanical study was taken from the fresh samples, as well as from samples preserved in alcohol (70\%)glycerin-water (1:1:1). The leaves, stems and inflorescence of the plant were separately air-dried, powdered to No. 40 and stored in well-closed containers for microscopical examination.

\section{The leaf}

\section{A- Macromorphology of the leaf}

The leaves (Figs. 1B\&2) are alternate, compound, paripinnate and exstipulate, each leaf has two stipules at its base but usually caducous. The leaflets are obovate-oblong with entire margin, rounded apex, symmetric base. They have a dark green upper surface and a paler lower one. Venation is pinnate reticulate. The leaflets measure $0.8-2 \mathrm{~cm}$ in length and $0.6-1 \mathrm{~cm}$ in width at the middle part. The leaf rachis is cylindrical, slightly grooved on the upper side where two longitudinal ridges run toward the upper side. It is green in colour, bearing three pairs of leaflets (the lowest is the smaller). There is a conical gland between the lowest pair of leaflets only. The petiole is similar to rachis, usually has a swollen base called pulvinus. The dry leaves are odourless and with unpleasant taste.

\section{B- Micromorphology of the leaf I) Micromorphology of the leaflet}

A transverse section in the lamina (Figs. 3A,3B,5A\&6A) through the midrib is somewhat plano-convex in outline. It reveals a dorsiventral structure with a continuous upper palisade consisting of a single row of columnar cells. A mass of collenchyma is abutting on the lower epidermis and formed of 1-2 rows. The midrib region shows a collateral vascular bundle consisting of a radiating xylem and a soft phloem. The pericycle is formed of two arcs of non-lignified fibers, the smaller arc is 


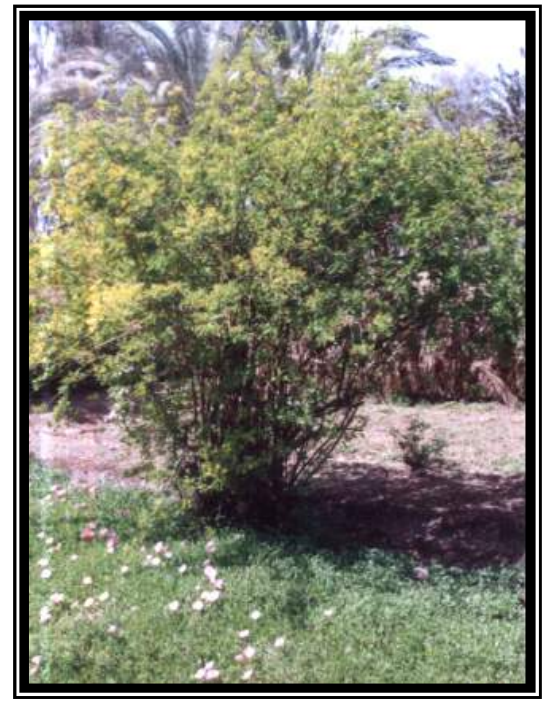

A

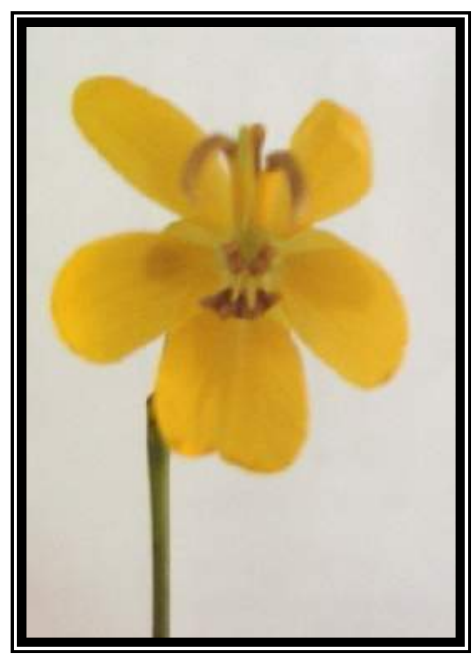

C

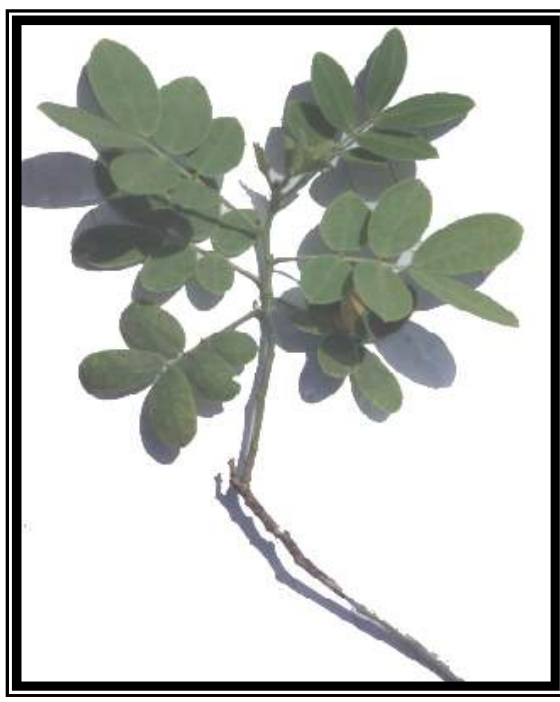

B

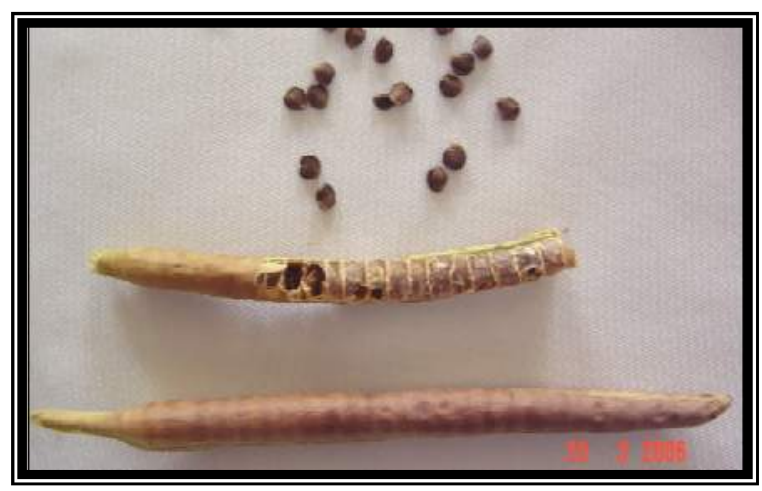

D

Fig. 1: A) Photo of the plant

B) Photo of a branch
$\mathrm{x} 1 / 75$
x $3 / 5$
x $3 / 2$
$\mathrm{x} 4 / 5$ 


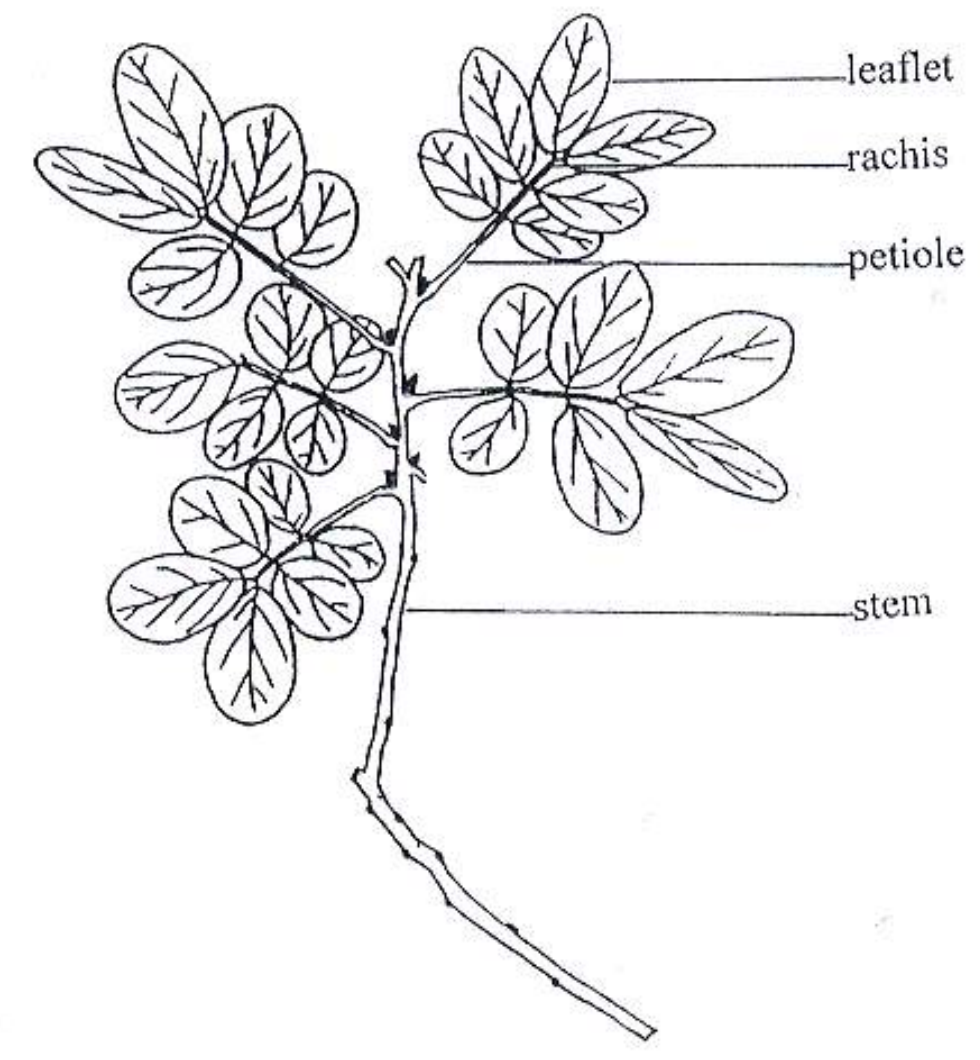

Fig. 2: Sketch of a branch

x 1 
situated above the vascular bundle but the larger one is crescent-shaped and situated below it. Numerous prismatic and cluster crystals of calcium oxalate are scattered in the cortical tissue and mesophyll. Hairs are absent.

\section{The epidermis}

\section{The upper epidermis}

The upper epidermis (Figs. $3 \mathrm{~B} \& 6 \mathrm{~A})$ is formed of one row of tangentially elongated cells as seen in transverse section while in surface view (Figs. 4A\&5B) the cells appear polygonal, usually isodiametric to slightly elongated cells with straight, beaded anticlinal walls and covered with thick smooth cuticle, measuring $16-24-32 €$ in length, $10-\underline{16}-22 €$ in width and 10-11-12 $€$ in height. Occasional oval paracytic stomata measuring 14-16-18 $€$ in length and $10-12-14 €$ in width are observed. Hairs are absent. Many epidermal cells contain mucilage which stained red with ruthenium red.

\section{The lower epidermis}

The lower epidermis (Figs. $3 \mathrm{~B} \& 6 \mathrm{~A})$ is formed of one row of subrectangular to square cells as seen in transverse section while in surface view (Figs. 4B\&5C) the cells appear polygonal, usually isodiametric with sinuous, thin anticlinal walls and covered with thick smooth cuticle, they measure 12-21-30 $€$ in length, 8$12-18 €$ in width and $4-5-6 €$ in height. Stomata are similar to those of the upper epidermis but they are more numerous. Hairs are absent. Many epidermal cells contain mucilage which stained red with ruthenium red.

\section{The mesophyll}

The mesophyll (Figs. 3A,5A\&6B) is heterogenous consisting of an upper zone of palisade which is continuous in the midrib region. It consists of one layer of columnar cells representing about one third of the distance between the two epidermises. The cells measure 18$\underline{23}-28 €$ in length and 4- $-5-6 €$ in width. The spongy tissue is formed of tangentially elongated to more or less rounded parenchyma with somewhat wide intercellular spaces. The cells with scattered prismatic and cluster crystals of calcium oxalate, in addition to few minute starch granules content.

\section{The cortical tissue}

The cortical tissue (Figs. 3B\&6A) is parenchymatous surrounding the main vascular bundle of the midrib. The cells show scattered prismatic crystals of calcium oxalate specially those surrounding the vascular bundle and forming a crystal sheath surrounding the pericyclic fibers. Cluster crystals of calcium oxalate are also present. There is 1-2 rows of collenchyma in the cortical region abutting on the lower epidermis.

\section{The vascular tissue}

The vascular tissue (Figs. $3 \mathrm{~B} \& 6 \mathrm{~A})$ is represented by the main vascular bundle of the midrib and the lateral small bundles of the veins.

The xylem is formed of lignified vessels and thin-walled wood parenchyma. The vessels are mainly spiral, sometimes sclariform thickened and measuring 3-9- $-15 €$ in 


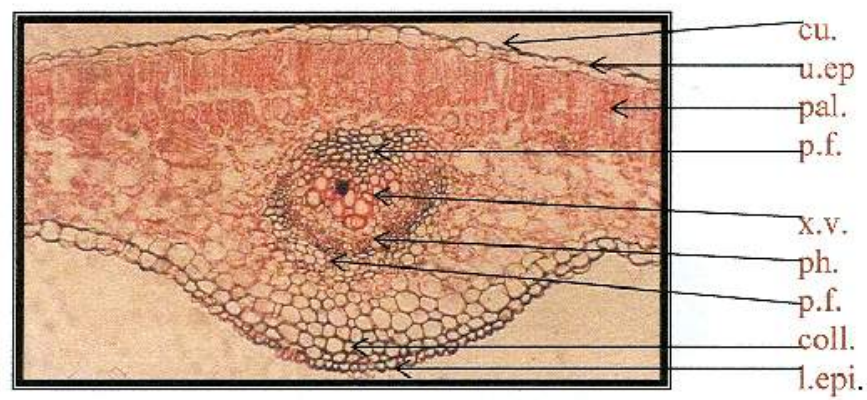

A

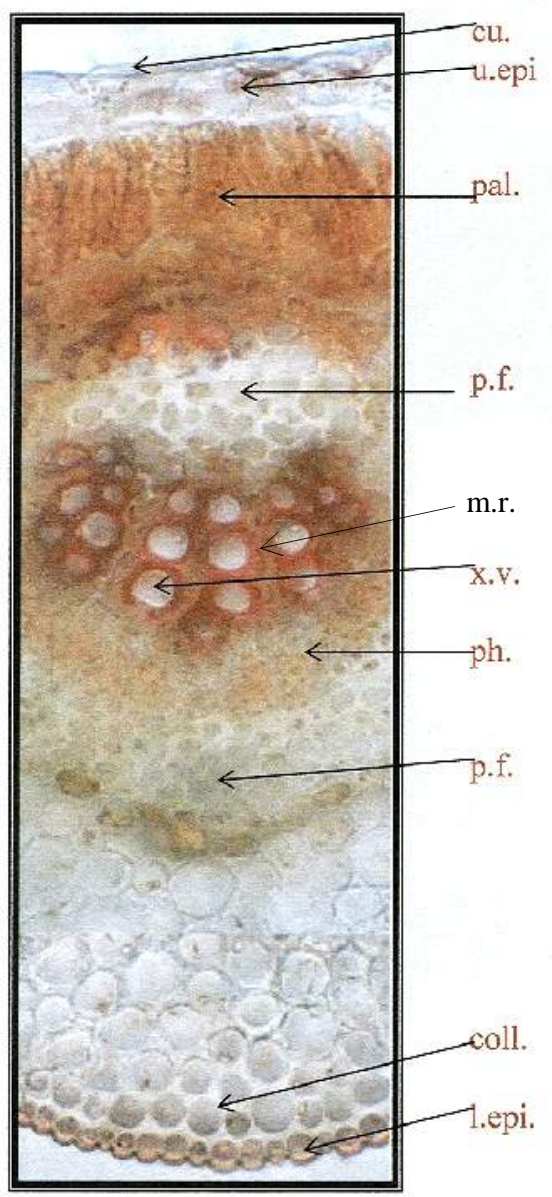

Fig. 3: A) Photo of T.S. of the leaflet $x 160$ B) Photo of detailed T.S. of the leaflet at midrib region

coll., collenchyma; cu., cuticle; l.epi., lower epidermis; m.r., medullary ray; p.f., pericyclic fiber; pal., palisade; ph., phloem; u.epi., upper epidermis; x.v., xylem vessel. 


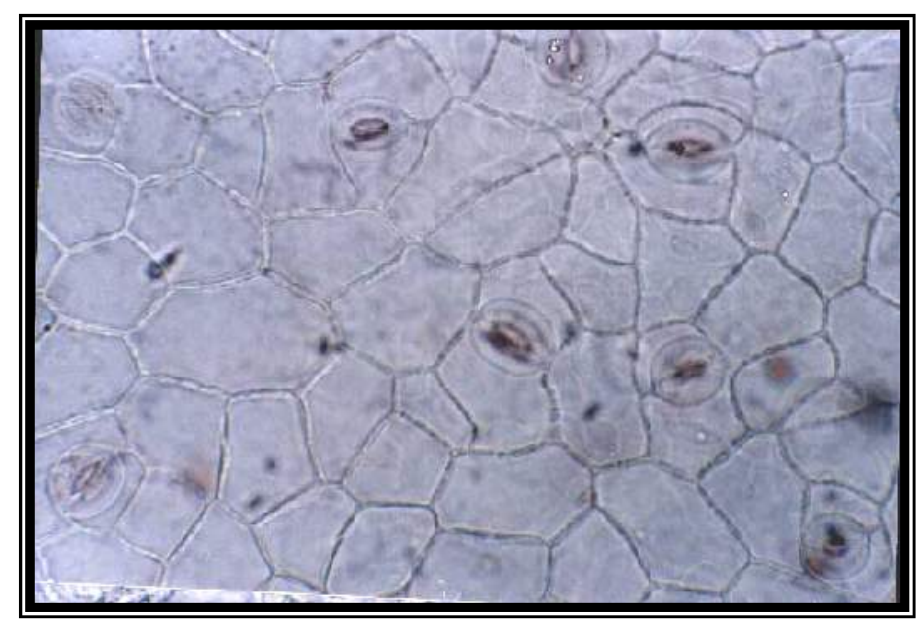

A

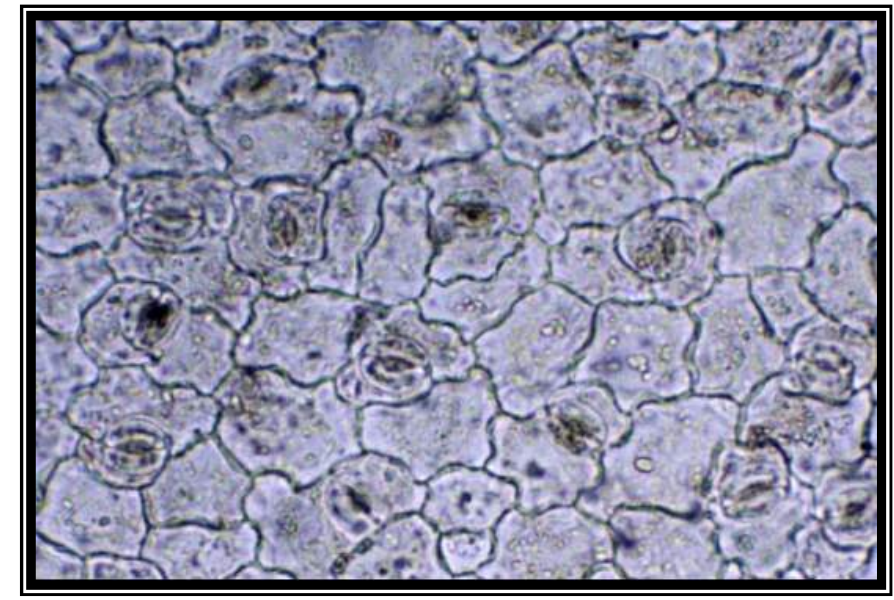

B

Fig. 4: Photo of surface preparation of the leaflet
A) Upper epidermis
x 500
B) Lower epidermis
x 500 


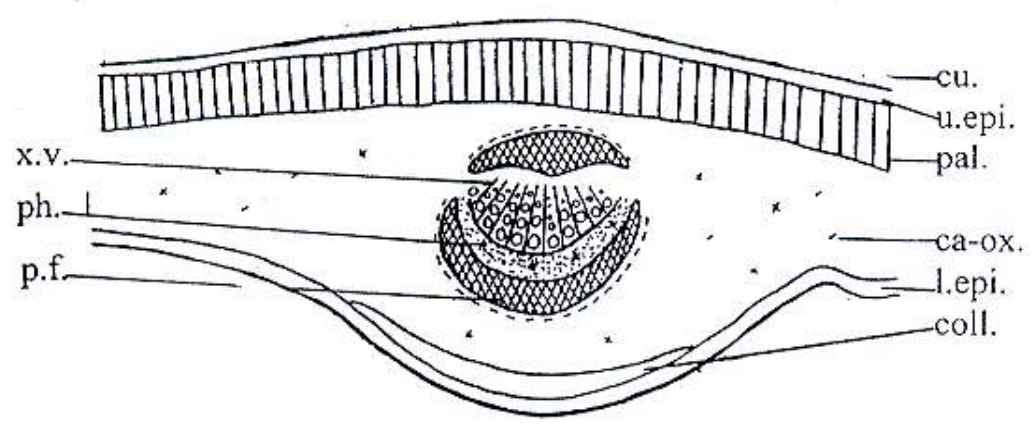

A

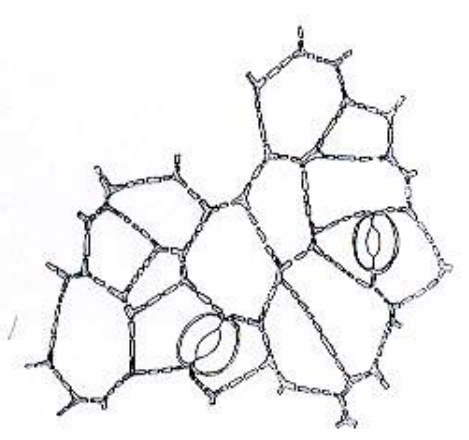

B

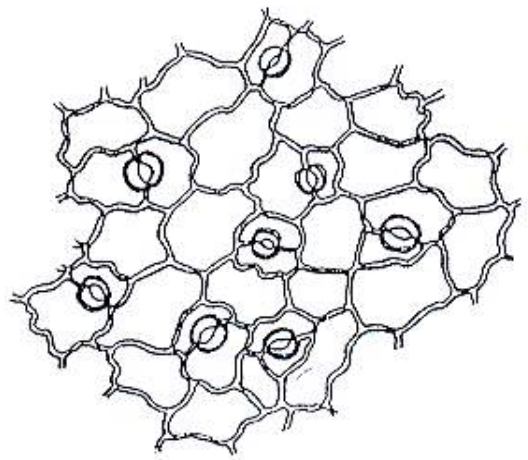

C

Fig. 5: A) Diagrammatic T.S. of the leaflet $\quad x 200$

B) Surface preparation of the upper epidermis of the leaflet $\mathrm{x} 400$

C) Surface preparation of the lower epidermis of the leaflet $\quad x 400$

ca-ox., calcium oxalate; coll., collenchyma; cu., cuticle; l.epi., lower epidermis; p.f., pericyclic fiber; pal., palisade; ph., phloem; u.epi., upper epidermis; x.v., xylem vessel. 

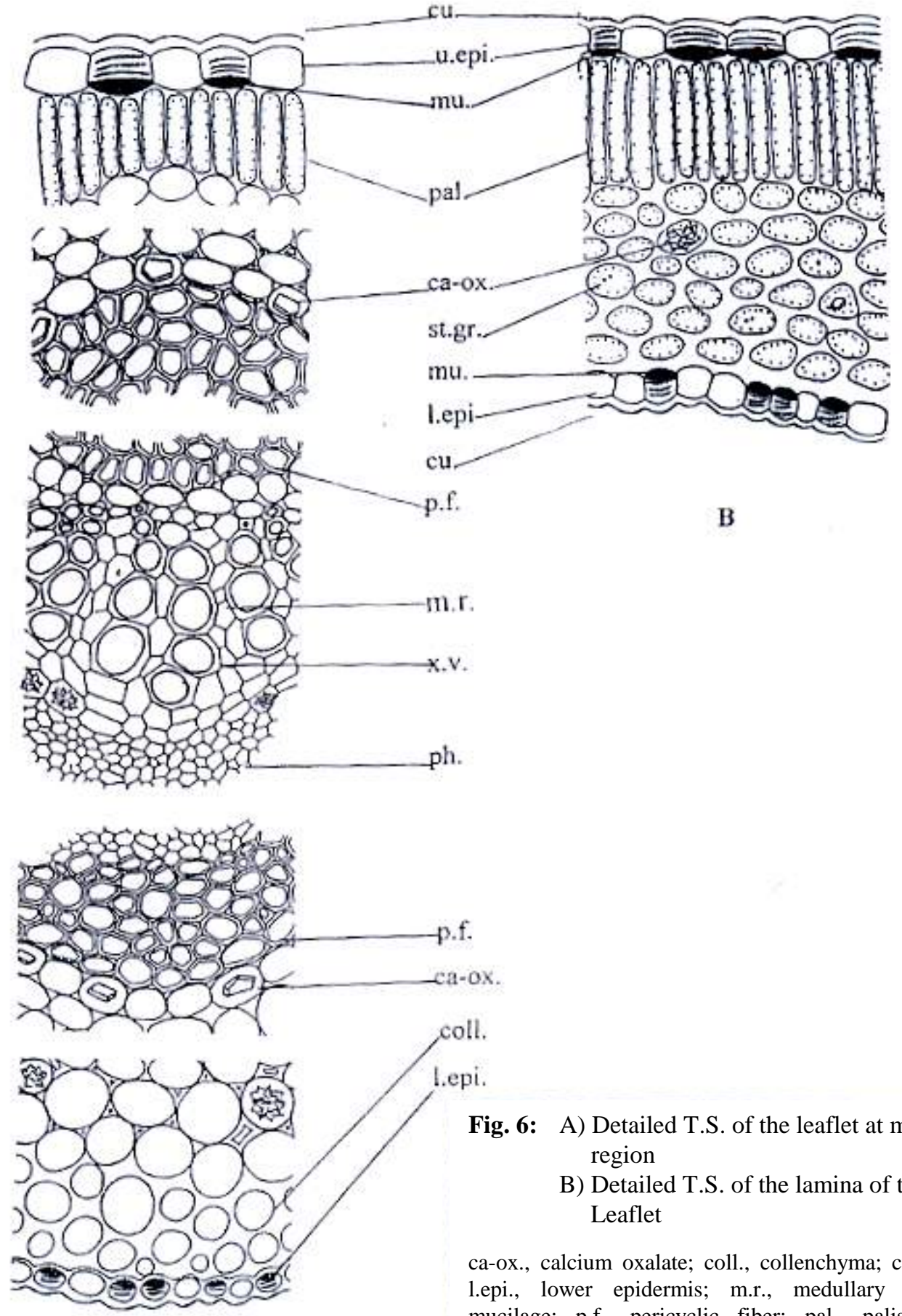

A p.f.

ca-ox.

coll.

l.epi.

Fig. 6: A) Detailed T.S. of the leaflet at midrib region

B) Detailed T.S. of the lamina of the Leaflet

ca-ox., calcium oxalate; coll., collenchyma; cu., cuticle; l.epi., lower epidermis; m.r., medullary ray; mu., mucilage; p.f., pericyclic fiber; pal., palisade; par., parenchyma; ph., phloem; st.gr., starch granules; u.epi., upper epidermis; x.v., xylem vessel. 
diameter. The medullary rays are formed of 1-2 rows of radially elongated, thin walled cellulosic cells.

The phloem is represented by a narrow crescent arc of soft elements below the xylem. Cluster crystals of calcium oxalate are scattered.

The pericycle is formed of two arcs of fibers. The upper one is formed of 6-8 rows of slightly lignified fibers. The lower one is formed of 4-6 rows of fibers. The fibers is elongated with a straight or irregular outline. It usually posseses non-lignified walls, wide lumen and acute to acuminate ends, measuring 260-294-327 $€$ in length and 6-9-12 $€$ in diameter. The fibers adjacent to the cortex are surrounded by parenchyma cells with scattered prismatic crystals of calcium oxalate and forming a crystal sheath.

\section{II) Micromorphology of the rachis}

A transverse section in the rachis (Figs. 7A\&8A) is more or less subrounded in outline. It shows a slight groove on the upper surface. It shows certain resemblance to the structure of the stem. Below the glabrous epidermis is a layer of hypodermal collenchyma. The cortical parenchyma is formed of thin-walled cells. The innermost layer of the cortex (The endodermis) is indistinguishable. The vascular system is represented by 3-4 collateral vascular bundles enclosing inbetween a wide pith. The whole are surrounded by a complete ring of lignified pericyclic fibers. The fibers adjacent to the cortex are surrounded by parenchyma cells with scattered prismatic crystals of calcium oxalate and forming a crystal sheath.

There are other two small vascular bundles being embedded in the convections. These two bundles are collateral consisting of a lower zone of inner radiating xylem and an upper arc of soft phloem followed externally by a large arc of lignified pericyclic fibers. Few minute starch granules as well as many clusters and prisms of calcium oxalate are scattered in the parenchyma.

\section{The epidermis}

The epidermis of the rachis (Figs. $7 \mathrm{~B} \& 8 \mathrm{C}$ ) is formed of one row of subrectangular to square cells as seen in transverse section while in surface view (Fig. 8B) the cells appear polygonal usually isodiametric with straight anticlinal walls covered with smooth cuticle. They measure 16-21$26 €$ in length, 12-17-22 $€$ in width and $6-\underline{8}-10 €$ in height. Stomata of paracytic type are observed. Hairs are absent.

The cortical tissue (Figs. 7B\&8C)

The outer collenchymatous layer consists of 1-2 rows of rounded or oval cells. The parenchymatous layer consists of 4-6 rows of thin-walled cells with intercellular spaces.

\section{The vascular tissue (Figs. 7B \&8C)}

The vascular bundles consist of an outer narrow region of phloem and an inner wide region of radiating xylem. The phloem is formed of sieve tubes, companion cells and phloem parenchyma. The xylem consists of 

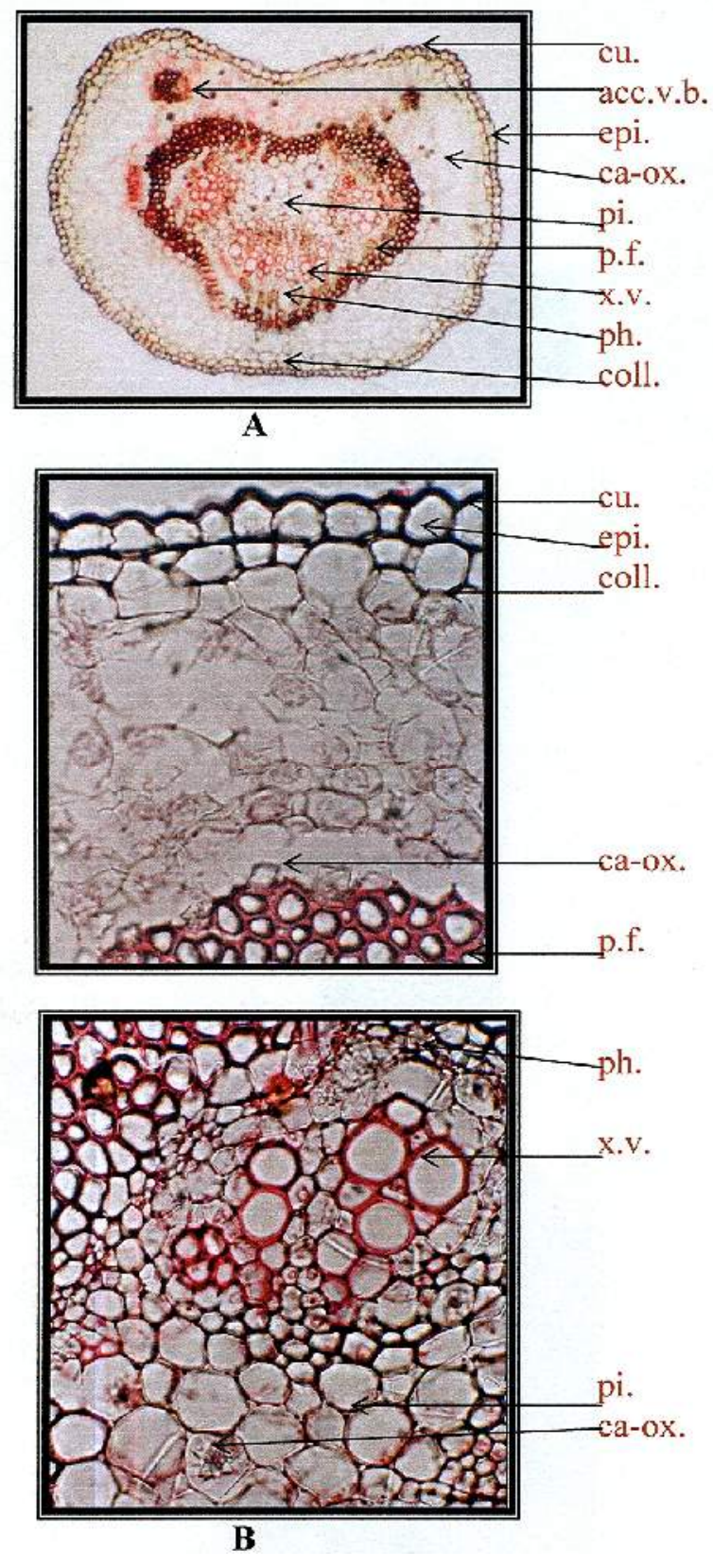

Fig. 7: A) Photo of T.S. of the rachis

$\mathrm{x} 100$

B) Photo of detailed T.S. of the rachis

x 600

acc.v.b., accessory vascular bundle; ca-ox., calcium oxalate; coll., collenchyma; cu., cuticle; epi., epidermis; p.f., pericyclic fiber; ph., phloem; pi., pith; x.v., xylem vessel. 


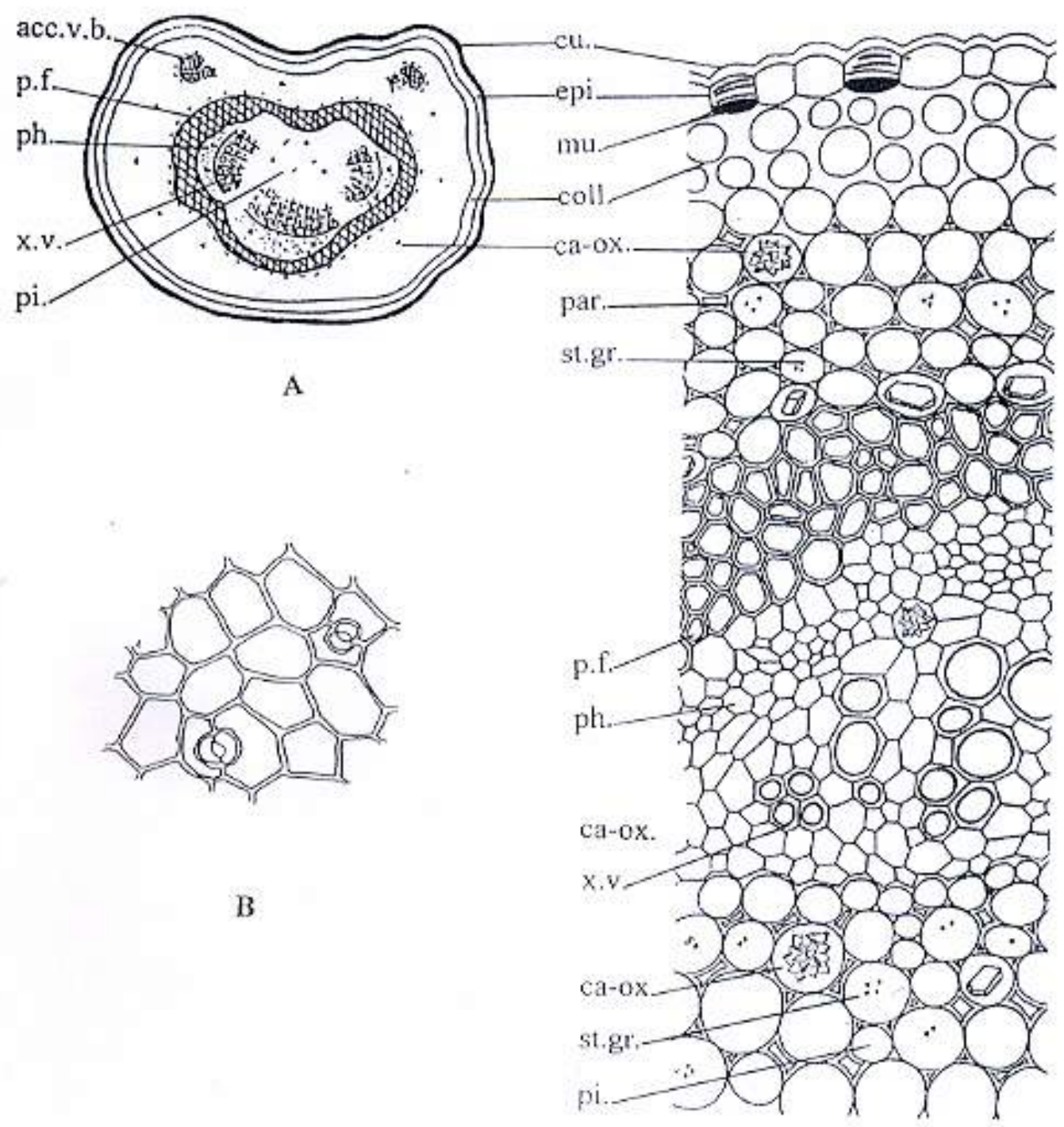

C

Fig. 8: A) Diagrammatic T.S. of the rachis

B) Surface preparation of the rachis

$\mathrm{x} 100$

$\mathrm{x} 400$

C) Detailed T.S. of the rachis

x 650

acc.v.b., accessory vascular bundle; ca-ox., calcium oxalate; coll., collenchyma; cu., cuticle; epi., epidermis; mu., mucilage; p.f., pericyclic fiber; par., parenchyma; ph., phloem; pi., pith; st.gr., starch granules; x.v., xylem vessel. 
vessels and wood parenchyma. The xylem vessels are lignified, having spiral and pitted thickening. They measure 5-10-15 $€$ in diameter. The wood parenchyma consists of sub rectangular cells. The medullary rays are uni- or bi- seriate thin-walled, radially elongated cells. The pericyclic ring is formed of 3-5 rows of polygonal lignified fibers. Each pericyclic fiber has a comparatively wide lumen, a straight lignified wall and a tapering apex. It measures 300$\underline{350}-400 €$ in length and $3-\underline{6}-9 €$ in diameter. The fibers adjacent to the cortex are surrounded by parenchyma cells containing prismatic crystals of calcium oxalate and forming a crystal sheath. The parenchyma cells of the pith are larger in size with thin walls. These cells contain prismatic and cluster crystals of calcium oxalate, measure 6-7-8 $€$ in length and 9-10$11 €$ in diameter respectively also few minute starch granules are present.

III) Micromorphology of the petiole

A transverse section in the petiole (Figs. 9A\&10A) is five-sided in outline, shows a slight groove on the upper surface. It carries certain resemblance to the structure of the stem. Below the glabrous epidermis is a layer of hypodermal collenchyma. The cortical parenchyma is formed of thin-walled cells. The innermost layer of the cortex (The endodermis) is indistinguishable. The vascular system is represented by 4-5 collateral vascular bundles enclosing inbetween a wide pith. The whole are surrounded by a discontinuous ring of lignified pericyclic fibers. The fibers are surrounded by a sheath of prismatic crystals of calcium oxalate. These patches of fibers are interrupted by parenchyma. There are other two small vascular bundles being embedded in the convections. These two bundles are collateral consisting of a lower zone of inner radiating xylem and an upper arc of soft phloem followed externally by a large arc of lignified pericyclic fibers. Few minute starch granules as well as many clusters and prisms of calcium oxalate are scattered in the parenchyma.

\section{The epidermis}

The epidermis of the petiole (Figs. $9 B \& 10 C)$ is formed of one row of sub-rectangular to square cells as seen in transverse section while in surface view (Fig. 10B) the cells appear polygonal usually isodiametric with straight anticlinal walls covered with smooth cuticle. They measure 18-23$28 €$ in length, $12-17-22 €$ in width and $7-\underline{8}-9 €$ in height. Stomata of paracytic type are observed. Hairs are absent.

The cortical tissue (Figs. 9B\&10C)

The outer collenchymatous layer consists of 1-2 rows of rounded or oval cells. The parenchymatous layer consists of 4-7 rows of thin walled cells having intercellular spaces.

The vascular tissue (Figs. 9B\&10C)

The vascular bundles consist of an outer narrow region of phloem and an inner wider region of radiating xylem. 


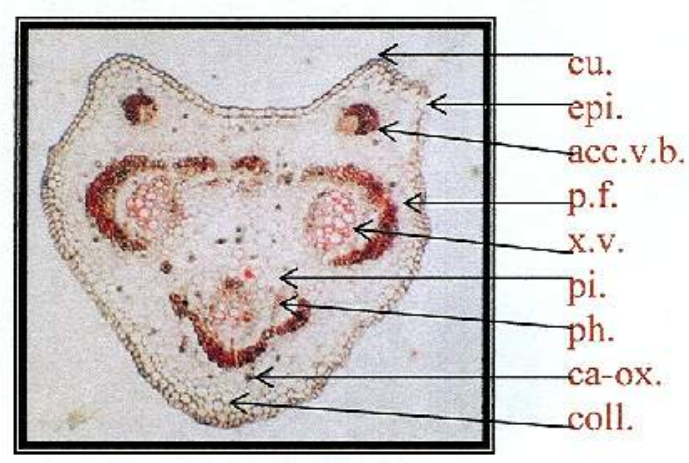

$\mathbf{A}$

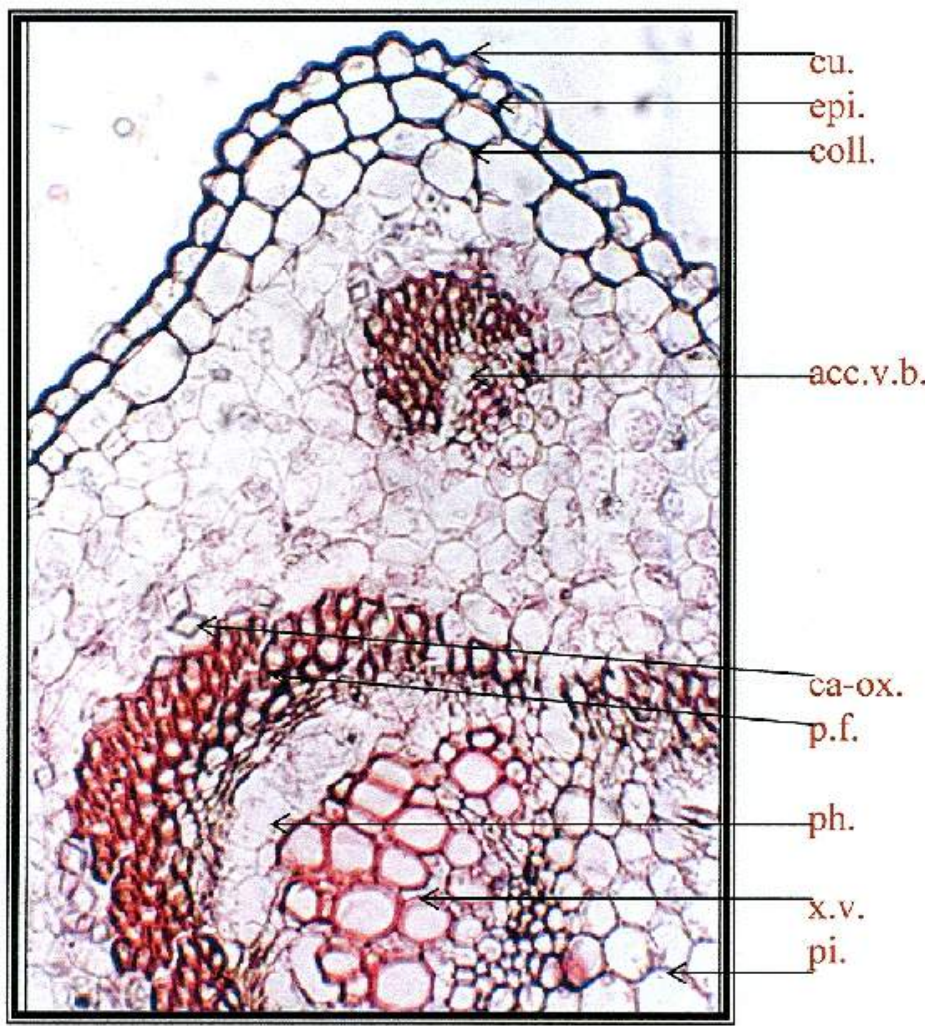

B

Fig. 9: A) Diagrammatic T.S. of the petiole

x 60

B) Detailed T.S. of the petiole

$\mathrm{x} 350$

acc.v.b., accessory vascular bundle; ca-ox., calcium oxalate; coll., collenchyma; cu., cuticle; epi., epidermis; p.f., pericyclic fiber; ph., phloem; pi., pith; x.v., xylem vessel. 


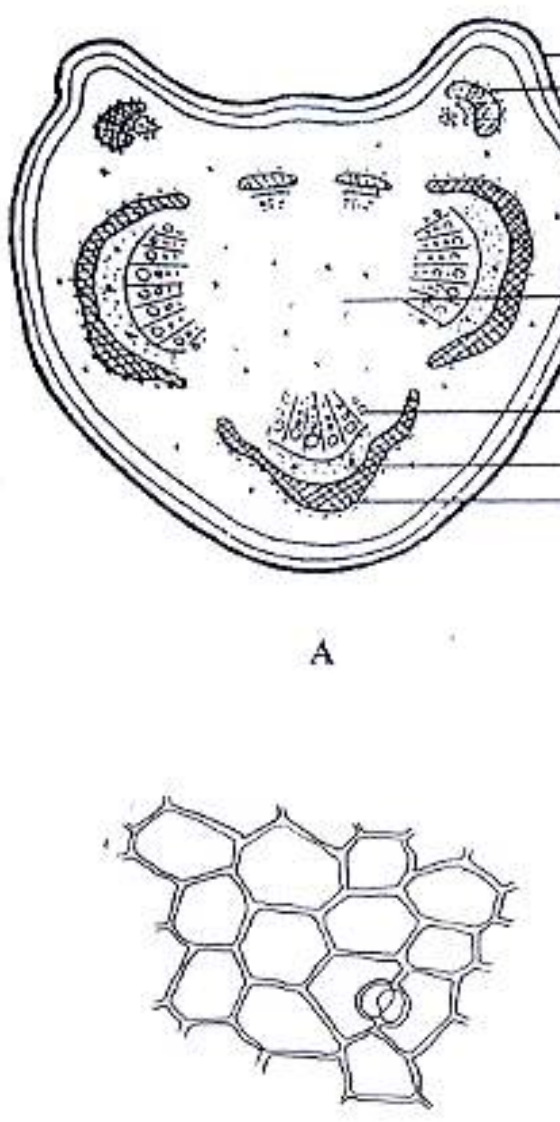

B
Fig. 10: A) Diagrammatic T.S. of the petiole

B) Surface preparation of the petiole

C) Detailed T.S. of the petiole cu.
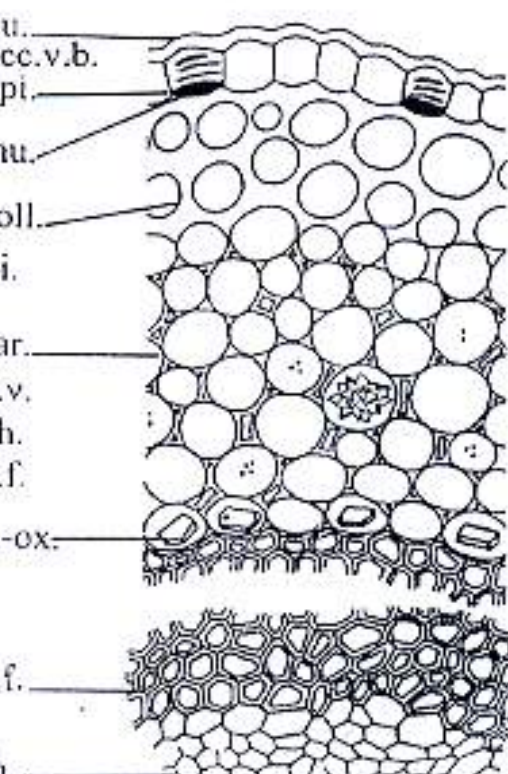

ph.
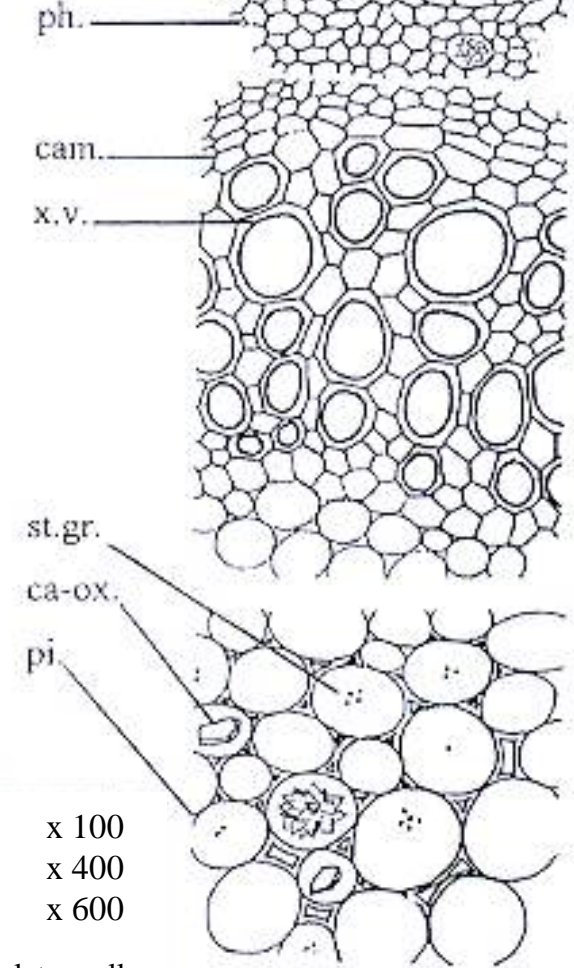

acc.v.b., accessory vascular bundle; ca-ox., calcium oxalate; coll., collenchyma; cu., cuticle; epi., epidermis; mu., mucilage; p.f., pericyclic fiber; par., parenchyma; ph., phloem; pi., pith; st.gr., starch granules; x.v., xylem vessel.

C 
The phloem is formed of sieve tubes, companion cells and phloem parenchyma. The xylem consists of vessels and wood parenchyma. The xylem vessels are lignified, having spiral and pitted thickening. They measure $5-11-17 €$ in diameter. The wood parenchyma consists of subrectangular cells. The medullary rays are uni- or bi- seriate and formed of thin-walled, radially elongated cells. The pericycle is formed of 4-6 rows of polygonal lignified fibers. Each pericyclic fiber has comparatively wide lumen, straight lignified wall and tapering apex. It measures 440$\underline{480}-520 €$ in length and $2-\underline{4}-6 €$ in diameter. The fibers adjacent to the cortex are surrounded by parenchyma cells containing prismatic crystals of calcium oxalate and forming a crystal sheath. The parenchyma cells of the pith are larger and thin walls. These cells contain prismatic and cluster crystals of calcium oxalate, measure 7-8 $-9 €$ in length and 9-11-13 $€$ in diameter respectively also few minute starch granules are present.

\section{The powder of the leaf}

The powder of the leaf (Fig. 11) is dark green in colour with a faint odour and an unpleasant taste. The main diagnostic microscopical elements are:

1- Fragments of the upper epidermis of the lamina in surface view consisting of polygonal, isodiametric to slightly elongated cells with straight anticlinal walls and covered with thick smooth cuticle. Stomata of paracytic type are observed. Hairs are absent.

2- Fragments of the lower epidermis of the lamina in surface view. The cells appeared polygonal, usually isodiametric with sinuous, thin anticlinal walls and covered with thick smooth cuticle. Stomata are similar to those of upper epidermis except that they are more numerous. Hairs are absent.

3- Fragments showing epidermis of the rachis in surface view consisting of polygonal, isodiametric to slightly elongated cells with straight anticlinal walls covered with smooth cuticle. Stomata of paracytic type are present.

4- Fragments of the palisade cells.

5- Fragments of parenchyma cells containing prisms and clusters crystals of calcium oxalate, sometimes these crystals appear free.

6- Solitary pericyclic fibers or groups surrounded by a crystal sheath with prismatic crystals of calcium oxalate. The fiber is elongated with a straight or irregular outline; it usually possesses nonlignified wall, wide lumen and acute to acuminate ends.

7- Fragments of lignified xylem vessels with spiral, sclariform and pitted thickening.

8- Absence of hairs.

* Numerical values of the leaflet Stomatal index

- for upper epidermis: 13-13.5-14

- for lower epidermis: 18.1-18.6-19.1 


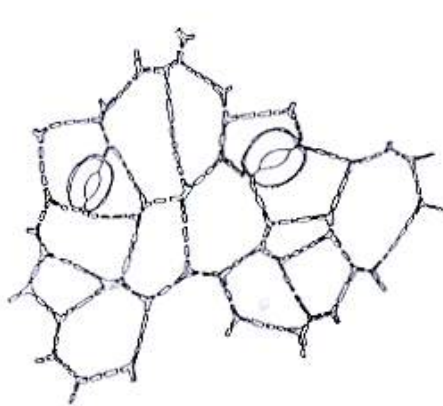

'u.epi.

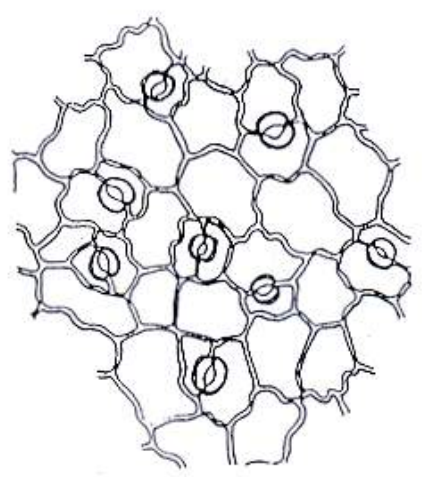

l.epi.

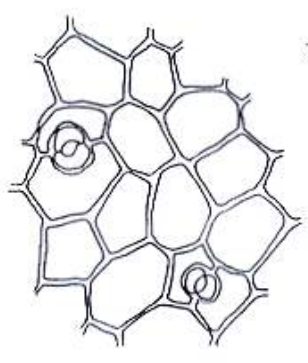

epi.ra

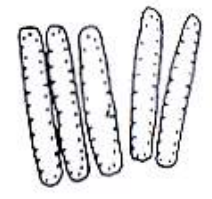

pal. $x 600$

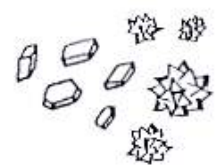

ca-ox. x 600

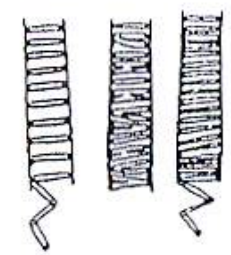

x.v.

cr.sh.

x 400

Fig. 11: Isolated elements of the leaf

ca-ox., calcium oxalate; cr.sh., crystal sheath; epi.ra., epidermis of rachis; l.epi., lower epidermis; p.f., pericyclic fiber; pal., palisade; st., stomata; u.epi., upper epidermis; x.v., xylem vessel.
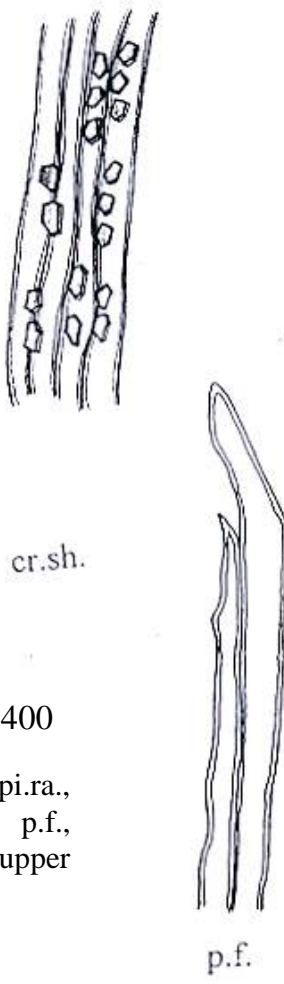
Palisade ratio: 6-10-14

Vein islet number: 18-20-22

\section{2- The stem}

\section{A- Macromorphology of the stem}

The main stem is erect, cylindrical, solid, woody, monopodially branched. It measures 2-3 meters in height and $15-20 \mathrm{~cm}$ in diameter at the middle part. The terminal and lateral branches are thinner, glabrous, green in colour and show short internodes. The terminal young parts of the stem are smooth and green in colour, while the older parts are rough, longitudinally striated, yellowish brown and carrying the scars of the fallen leaves. The stem is odourless with a slight bitter taste.

\section{B- Micromorphology of the stem}

A transverse section in the young stem (Figs. 12A\&14A) is nearly fivesided in outline. The section shows an epidermis followed by a comparatively narrow cortex lined with a pericycle surrounding a continuous ring of vascular tissue with wide parenchymatous pith in the center. The phloem zone is separated from the xylem by several layers of thin walled cambial cells.

\section{The epidermis}

The epidermis (Figs. 12B\&15) is formed of one row of usually sub rectangular cells as seen in transverse section while in surface view (Fig. 14C) the cells appear polygonal, isodiametric with straight anticlinal walls covered with smooth cuticle and measuring 10-16-22 $€$ in length, 6-10-14 $€$ in width and 9-10-11 $€$ in height. Stomata of paracytic type are rarely present. Hairs are absent. Many epidermal cells contain mucilage which stains red with ruthenium red.

\section{The cortex}

The cortex (Figs. 12B\&15) is formed of an outer continuous zone of collenchyma arranged in 1-2 rows, followed by 4-6 rows of parenchymatous cells. These parenchyma cells contain prismatic and cluster crystals of calcium oxalate, as well as few minute starch granules. The endodermis is indistinguishable.

\section{The pericycle}

The pericycle (Figs. 12B\&15) is formed of a continuous ring of lignified fibers. The fiber is long, having somewhat straight wall, wide lumen and a tapering apex. It measures from 500-580-660 $€$ in length and 6-10-14 € in diameter. The fibers are surrounded by parenchyma cells containing prismatic crystals of calcium oxalate forming a crystal sheath. The prisms measure 4-5.5-7€ in length. There is another discontinuous ring of lignified fibers situated on the inner side of the vascular tissue. These patches similar to those of the outer ring but separated by parenchyma cells and represent an internal pericycle.

\section{The phloem}

The phloem (Figs. 12B\&15) is formed mainly of phloem parenchyma, sieve tubes and companion cells. The phloem 
parenchyma are sub-rectangular to polyhedral in shape, contain cluster crystals of calcium oxalate, and traversed by primary and secondary medullary rays with thin-walled cells.

\section{The xylem}

The xylem (Figs. 12B\&15) is formed of lignified vessels, fibers, tracheids and wood parenchyma.It is traversed by usually uni-, bi, or multiserriate medullary rays. The medullary rays are formed of elongated sub-rectangular cells with pitted and slightly lignified walls. The vessels are mainly pitted, some with spiral thickening and measuring 5-12$19 €$ in diameter.

Tracheids are elongated with blunt ends, the walls are lignified and show simple pits, they measure 40-60-80 $€$ in length and 16-18-20 $€$ in diameter. The wood parenchyma is rectangular with pitted lignified walls and measuring 18-22-26 $€$ in length and $10-12-14 €$ in width. The wood fiber is elongated and showing a comparatively narrow lumen and an acute apex. It has a straight or irregular lignified wall and measuring $300-\underline{320}-340 €$ in length and 4- $\underline{8}-12 €$ in diameter.

\section{The pith}

The pith (Figs. 12B\&15) is formed of a wide zone of more or less rounded parenchymatous cells having pitted and non-lignified walls. These parenchyma cells contain prismatic and cluster crystals of calcium oxalate, measuring $6-\underline{8}-10 €$ in length and $8-\underline{10}-12 €$ in diameter respectively. Few minute starch granules are present.

A transverse section in the old stem (Figs. 13,14B\&14D) is more or less circular in outline and showing several rows of non lignified suberised, tangentially elongated cork cells. The secondary cortex consists of an outer zone of collenchyma arranged in 4-5 rows followed by few layers of regular parenchymatous cells which contain starch granules, prisms and cluster crystals of calcium oxalate. The pericycle consists of isolated groups of lignified fibers surrounded by parenchyma which contain prisms of calcium oxalate. The phloem shows small groups of phloem fibers. The secondary xylem consists of larger xylem vessels and narrower central pith. The pith consists of large, nearly rounded cells with pitted, thick and slightly lignified walls. They contain starch granules, prisms and cluster crystals of calcium oxalate similar to those seen in the secondary cortex.

\section{The powder of the stem}

The powder of the stem (Fig. 16) is yellowish green in colour with a faint odour and a slight bitter taste. The main diagnostic microscopical elements are:

1- Fragments of the epidermal cells, which are polygonal, isodiametric with straight anticlinal walls covered with smooth cuticle. Hairs and stomata are absent. 

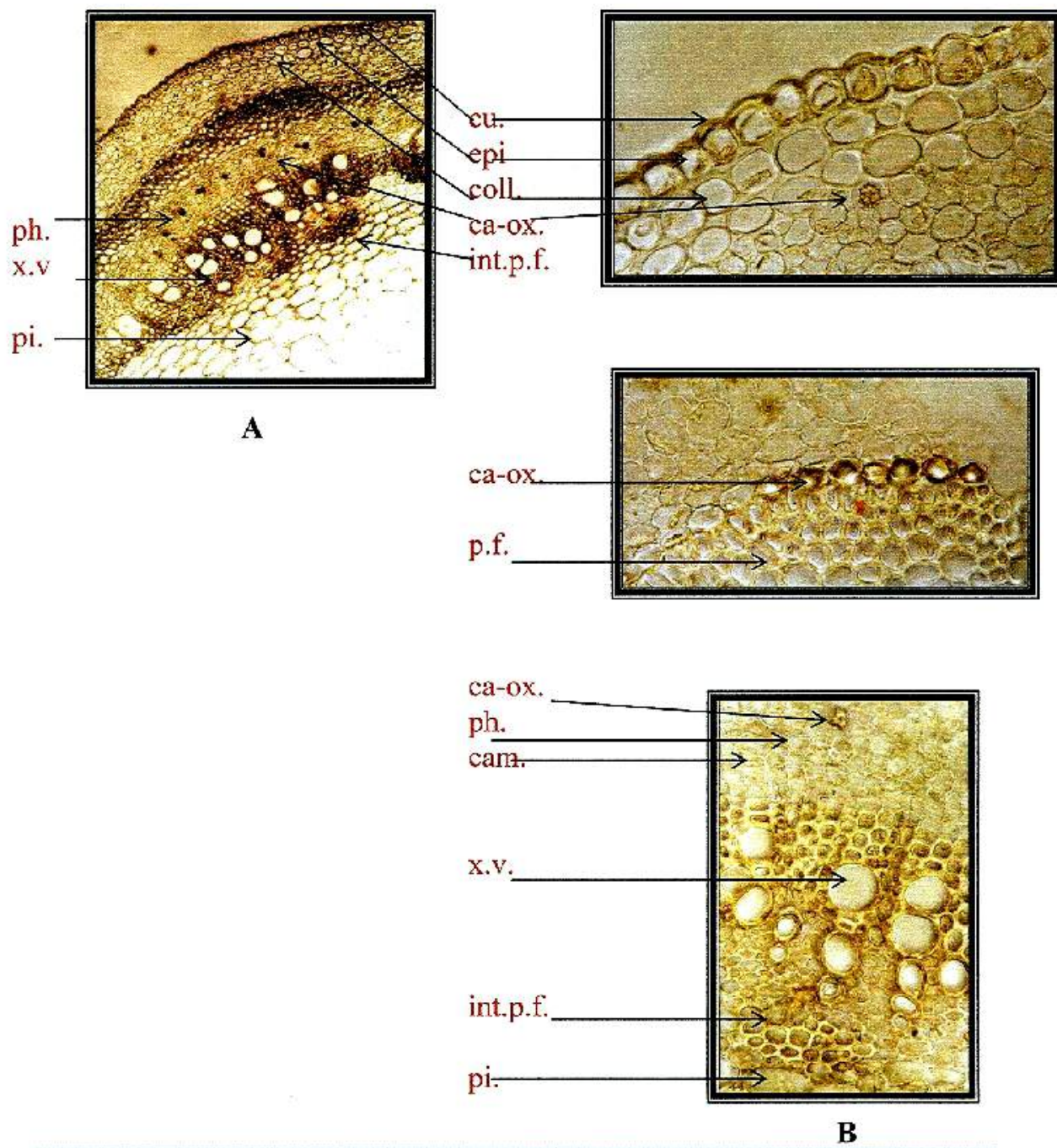

Fig. 12: A) Photo of T.S. of young stem

$\mathrm{x} 100$

B) Photo of detailed T.S. of young stem

x 300

ca-ox., calcium oxalate; cam., cambium; coll., collenchyma; cu., cuticle; epi., epidermis; int.p.f., internal pericyclic fiber; p.f., pericyclic fiber; ph., phloem; pi., pith; x.v., xylem vessel. 


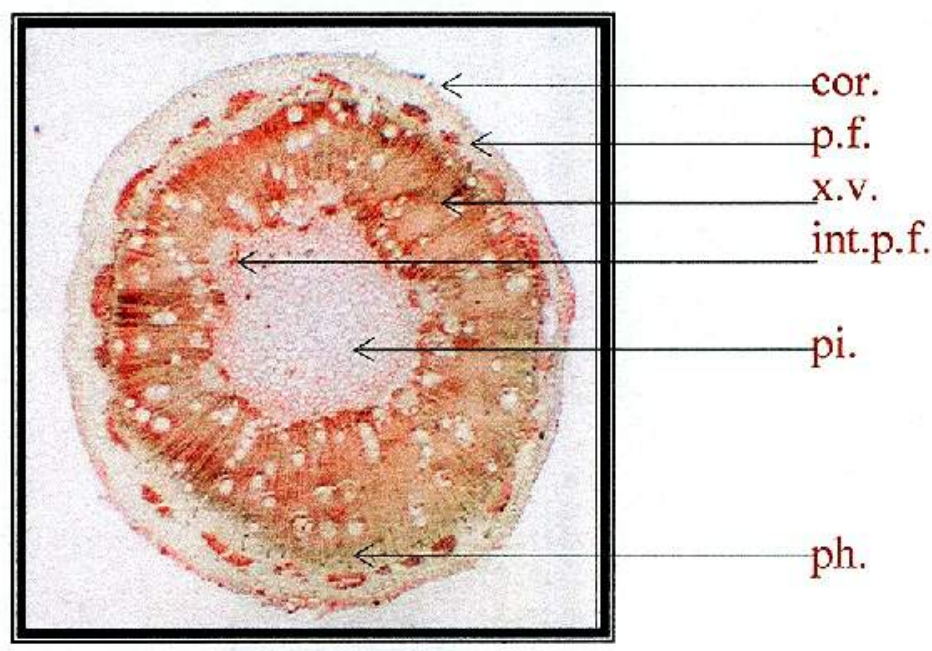

A

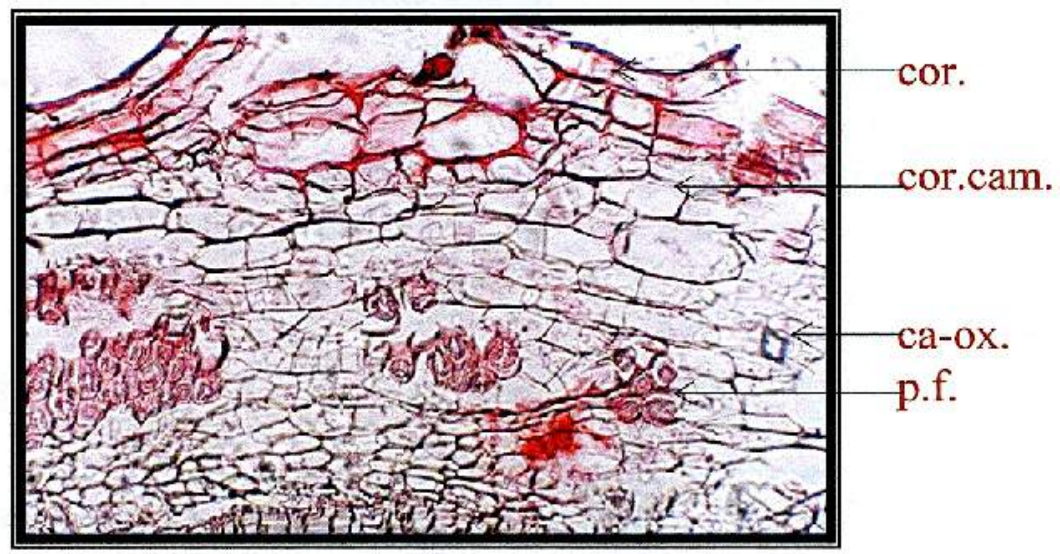

B

Fig. 13: A) Photo of T.S. of old stem

B) Photo of detailed T.S. of old stem

\section{x 35}

$\mathrm{x} 400$

ca-ox., calcium oxalate; cor., cork; cor.cam., cork cambium; int.p.f., internal pericyclic fiber; p.f., pericyclic fiber; ph., phloem; pi., pith; x.v., xylem vessel. 


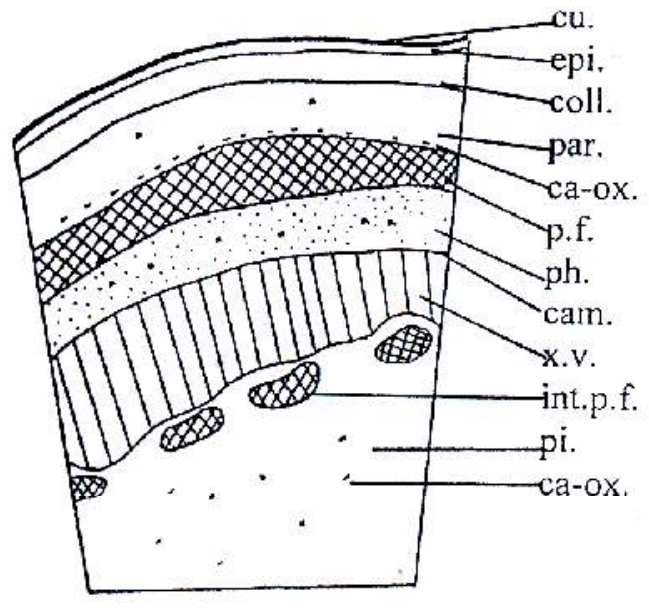

A

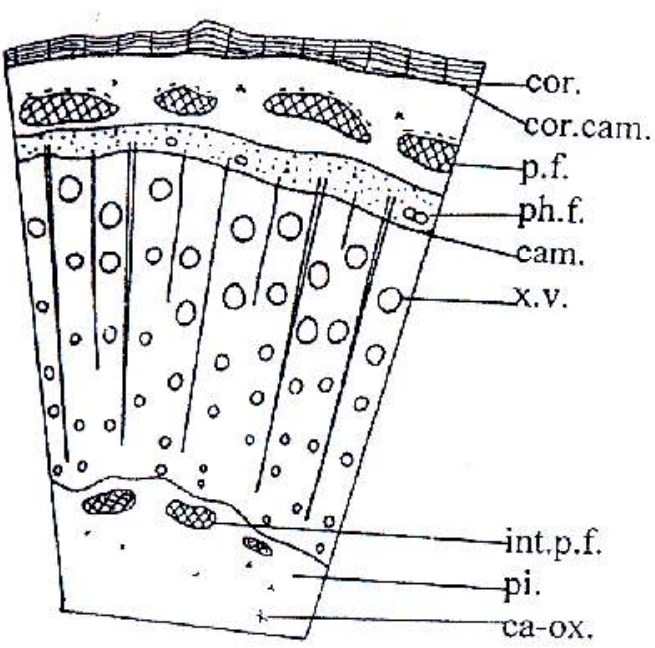

B

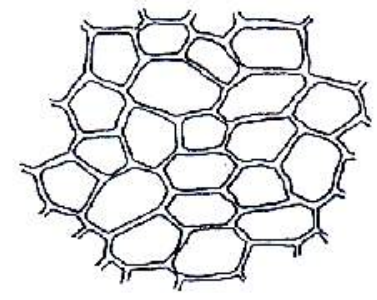

C

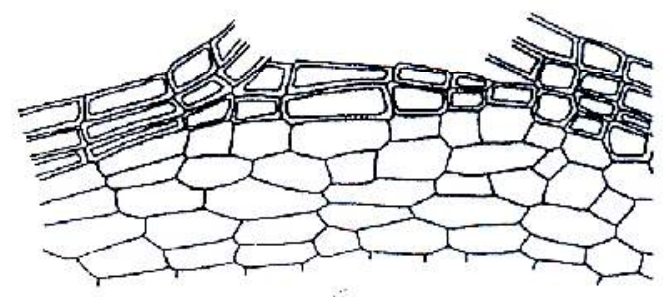

D

Fig. 14: A) Diagrammatic T.S. of young stem

$\mathrm{x} 150$

B) Diagrammatic T.S. of old stem

$\mathrm{x} 100$

C) Surface preparation of young stem

x 400

D) Cork

$\mathrm{x} 300$

ca-ox., calcium oxalate; cam., cambium; coll., collenchyma; cor., cork; cor.cam., cork cambium; cu., cuticle; epi., epidermis; int.p.f., internal pericyclic fiber; p.f., pericyclic fiber; par., parenchyma; ph., phloem; ph.f., phloem fiber; pi., pith; x.v., xylem vessel. 

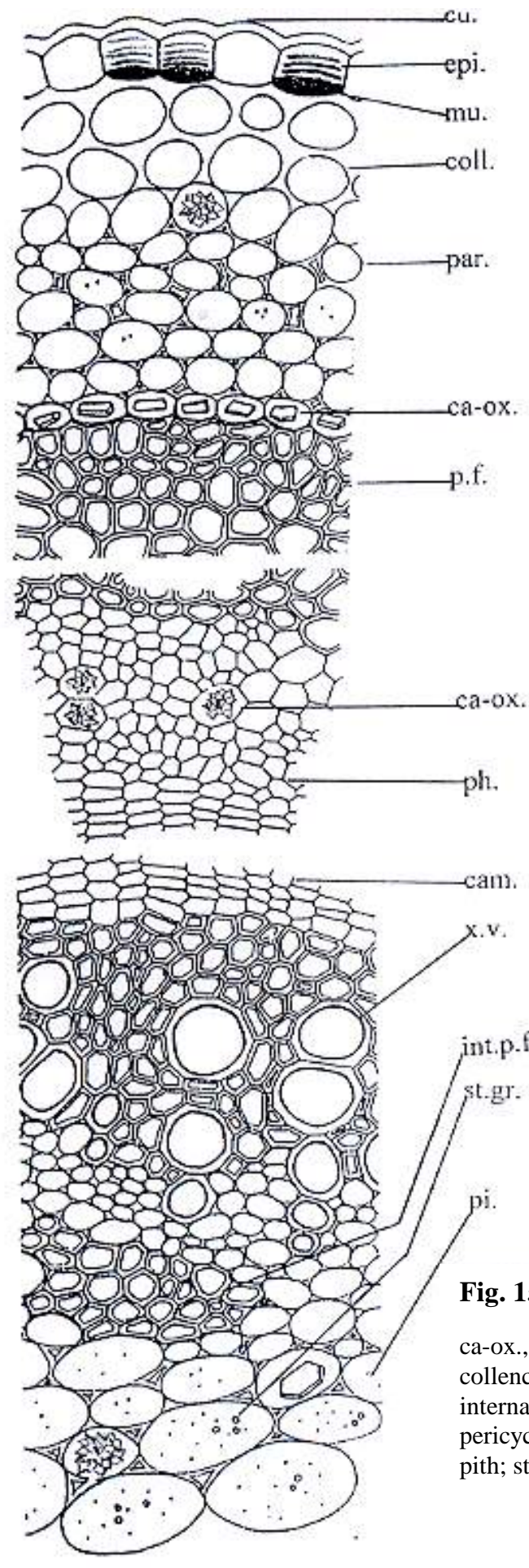

cani.

t.p. $f$.

$/_{\text {st.gr. }}^{\text {int.p. }}$

Fig. 15: Detailed T.S. of young stem

x 550

ca-ox., calcium oxalate; cam., cambium; coll., collenchyma; cu., cuticle; epi., epidermis; int.p.f., internal pericyclic fiber; mu., mucilage; p.f., pericyclic fiber; par., parenchyma; ph., phloem; pi., pith; st.gr., starch granules; x.v., xylem vessel. 


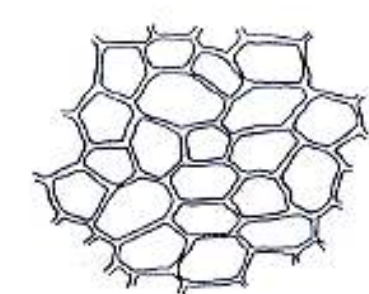

epi.
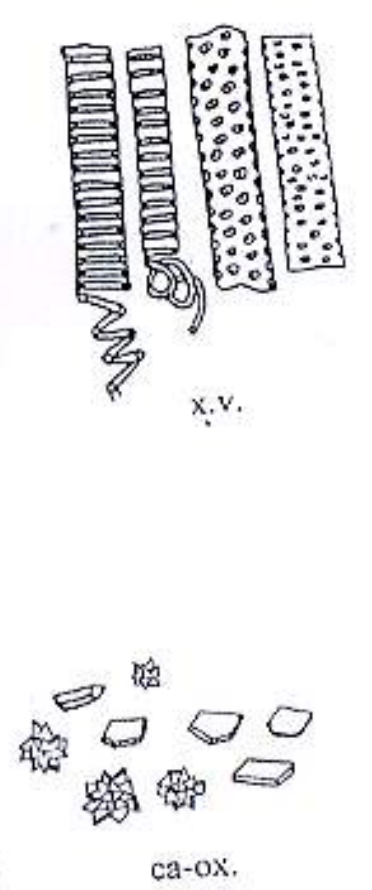
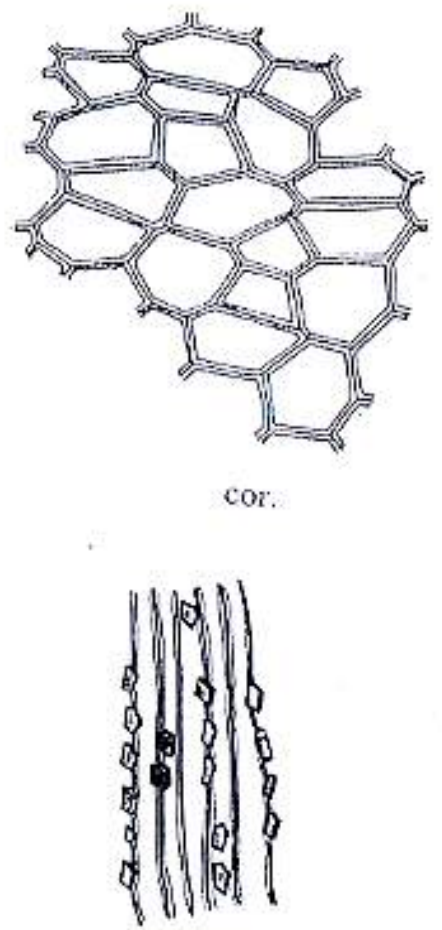

cr.sh.

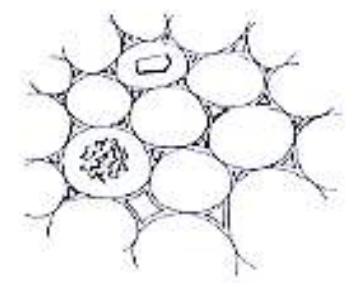

pi.

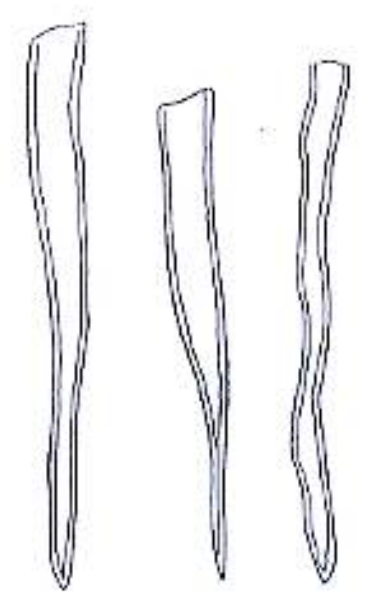

p.f.

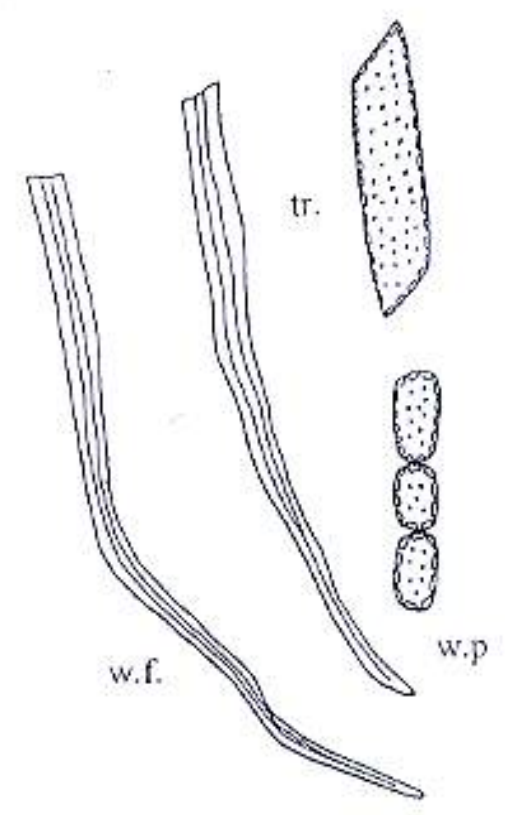

x 400

Fig. 16: Isolated elements of the stem

ca-ox., calcium oxalate; cor., cork; cr.sh., crystal sheath; epi., epidermis; p.f., pericyclic fiber; pi., pith; tr., tracheid; w.f., wood fiber; w.p., wood parenchyma; x.v., xylem vessel. 
2- Fragments of more or less rounded parenchyma cells of the pith with pitted and non-lignified walls.

3- Fragments of cork cells from the very old stem consisting of polygonal cells with slightly thick lignified walls

4- Scattered free prisms and cluster crystals of calcium oxalate.

5- Fragments of lignified pericyclic fibers, either solitary or in groups surrounded by parenchyma containing prismatic crystals of calcium oxalate. The fiber is long, having somewhat straight wall, wide lumen and a tapering apex.

6- Fragments of xylem vessels, which are lignified, mainly pitted but sometimes spirally thickened.

7- Fragments of lignified wood fibers with narrow lumena, an acute apex and straight or slightly irregular walls.

8- Fragments of wood parenchyma, which have slight lignified and pitted walls.

9- Fragments of elongated tracheids with lignified pitted walls and blunt ends.

\section{3- The inflorescence}

\section{A- Macromorphology of the inflorescence}

The flowers are grouped in branched or unbranched dense terminal racemes (Figs. 17A\&18A). The inflorescence has a long, straight, cylindrical, green peduncle which has a smooth surface and bears flowers in an alternate manner. The inflorescence has faint odour and bitter taste.
The flower is shortly pedicellate, abracteate, hermaphrodite, zygomorphic, pentamerous, and hypogynous. It possesses the following floral formula (Fig. 18C):

\section{The calyx}

$$
\bullet,,, \mathrm{K}_{5}, \mathrm{C}_{5}, \mathrm{~A}_{7+3}, \mathrm{G}_{1}
$$

The calyx is persistant, polysepalous of five sessile imbricate sepals. The sepal is glabrous, lanceolate in shap with acute apex, entire margin and greenish yellow colour, measuring $0.5-0.7 \mathrm{~cm}$ in length and $0.2-0.4 \mathrm{~cm}$ in width.

\section{The corolla}

The corolla is polypetalous, of five free, bright yellow petals arranged in one whorl. Each petal is ovate with rounded apex and entire margin. The surface is glabrous and shows a reticulate venation. It measures $1.5-2 \mathrm{~cm}$ in length and 0.5 $0.7 \mathrm{~cm}$ in width at the middle.

\section{The androecium}

The androecium consists of ten free stamens of unequal length, the three upper ones are small and sterile (staminodes), four are median-sized and three are large and sickle shaped. The filaments are filiform and yellow in colour while anthers are brown, basifixed and each one has two anther lobes.

\section{The gynoecium}

The gynoecium is superior, monocarpellary, unilocular and green in colour. The ovary is elongated, containing numerous ovules arranged on a marginal placenta. The stigma is reduced and curved. 


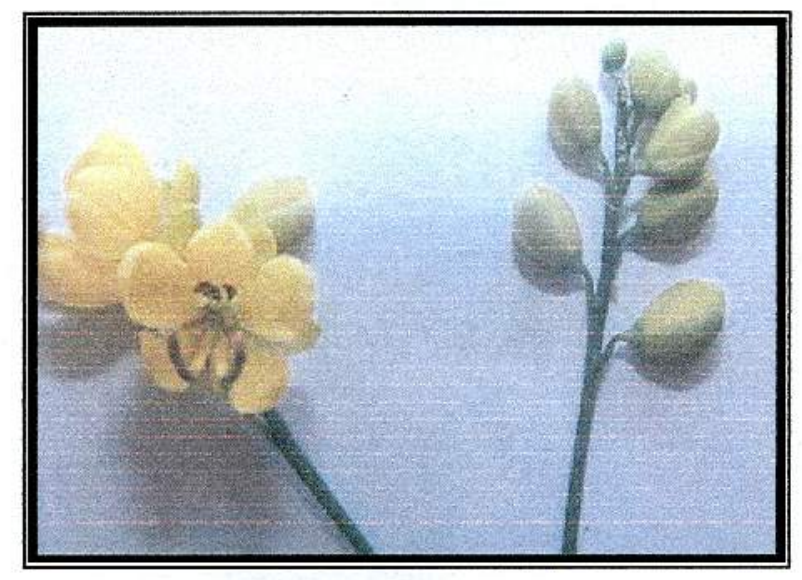

A

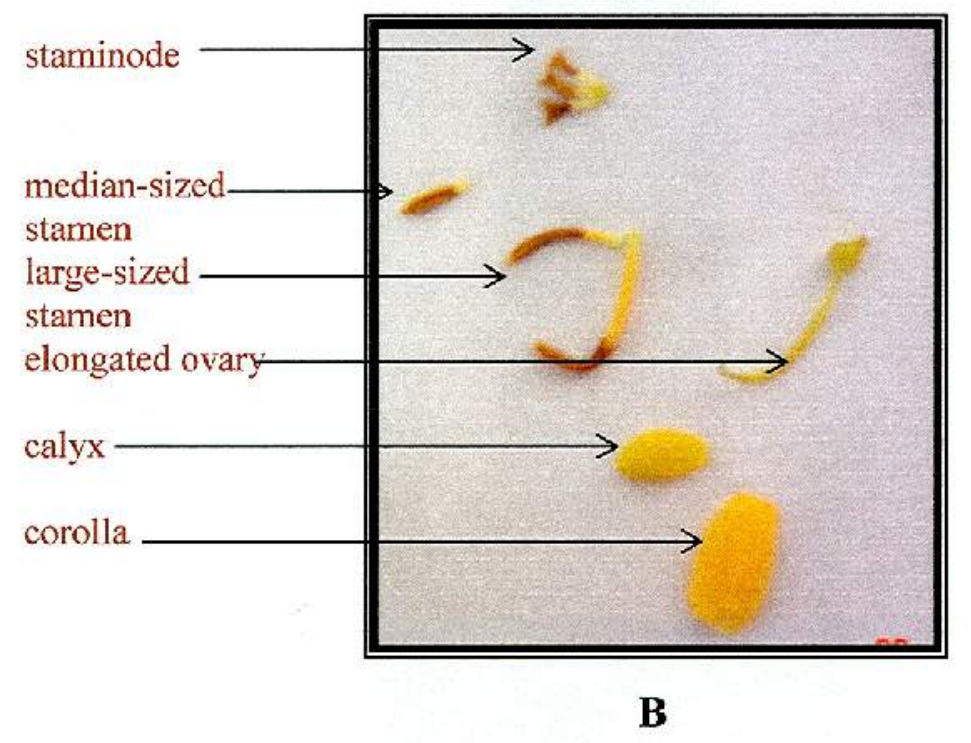

Fig. 17: A) Photo of an inflorescence

$\mathrm{x} 1$

B) Photo of floral parts

x $3 / 2$ 


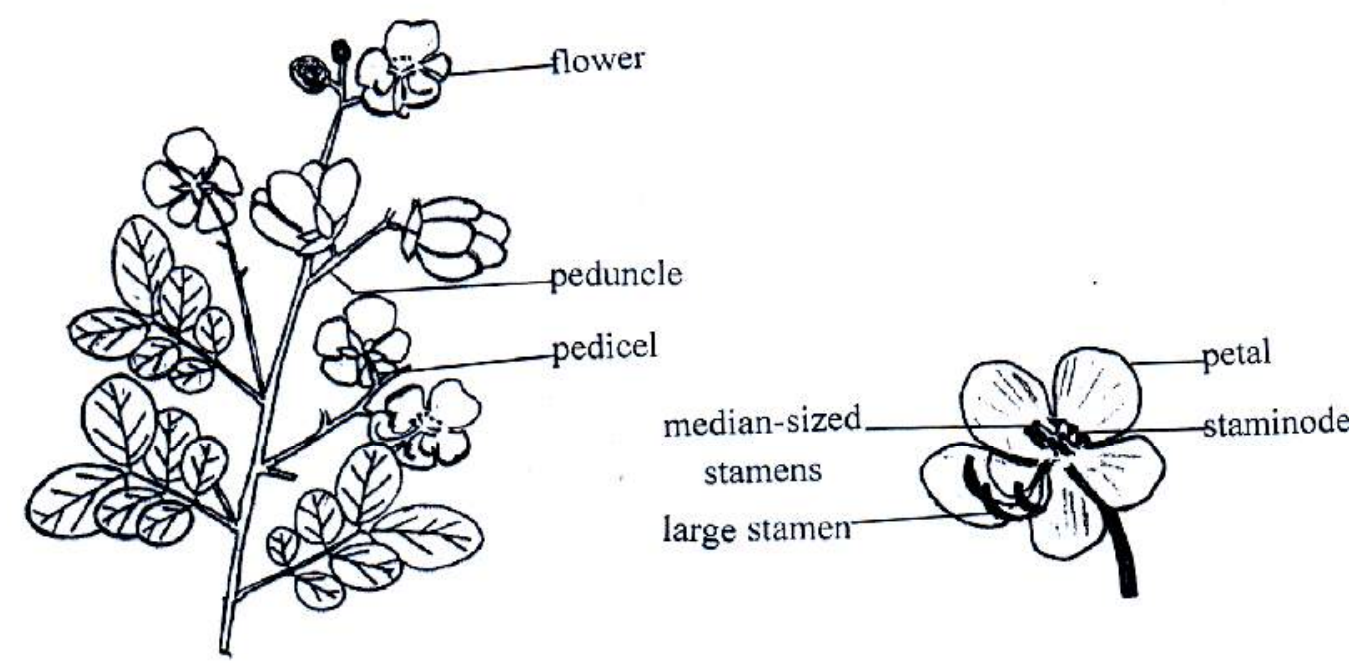

B

A

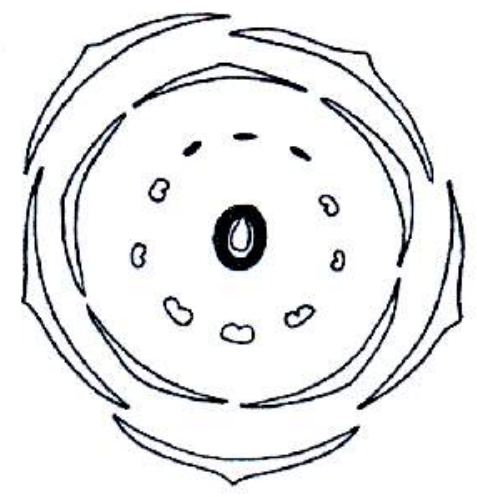

C

$$
\%, \underset{+}{\text { ว }}, \mathbf{K}_{5}, \mathbf{C}_{5}, \mathbf{A}_{7+3}, \mathbf{G}_{1}
$$

Fig. 18: A) Sketch of a flowering branch

B) Sketch of a flower

x $1 / 2$

C) Floral diagram 


\section{The pedicle}

The pedicle is short, straight, green in colour with smooth surface.

\section{B- Micromorphology of the inflorescence}

I) Micromorphology of the flower

\section{1- The calyx}

A transverse section in the middle part of the sepals appears somewhat concavo-convex in outline. It comprises an outer and an inner epidermises enclosing in-between a homogenous mesophyll traversed by several collateral vascular strands.

\section{A- The outer epidermis}

The outer epidermis of the sepals shows some variations in the cell shape and size at different regions.

\section{The apical and the middle regions} (Figs. 19D\&19E)

The cells in surface view are polygonal, isodiametric to slightly elongated with wavy anticlinal walls covered with striated cuticle. They measure 10-14-18 $€$ in length and 6.510-13.5 $€$ in width. Stomata of paracytic type are present.

\section{The basal region (Fig. 19F)}

The cells are similar to those of the previous regions but the walls are straight. They measure $8-\underline{13}-18 €$ in length and 6.5-10-13.5 € in width.

\section{B- The inner epidermis (Figs.}

\section{A,19B\&19C)}

The inner epidermis of the sepals shows similar cells as in the apical, middle and basal regions but they are different in size. The cells are polygonal, isodiametric to slightly elongated, with straight anticlinal walls covered with a striated cuticle. Stomata of paracytic type are present. The cells of the apical region measure $6-\underline{12-18} €$ in length and 5- $\underline{-5}-12 €$ in width, the cells of the middle region measure $10-18-26 €$ in length and 7 $11-15 €$ in width, the cells of the basal region measure 8-14-20 $€$ in length and 6-9-12 € in width.

\section{2- The corolla}

A transverse section in the middle portion of the petals appears somewhat concave to convex in outline. It comprises an outer and an inner epidermises enclosing inbetween a homogenous mesophyll traversed by several collateral vascular strands.

\section{A- The outer epidermis The apical region (Fig. 20A)}

The cells in surface view are polygonal, isodiametric to slightly elongated with wavy anticlinal walls covered with striated cuticle. They measure 11-14.5-18 $€$ in length and 57.5-10 $€$ in width. The cells are papillosed and contain prismatic crystals of calcium oxalate. Stomata are not observed.

\section{The middle region (Fig. 20B)}

The cells are similar to those of the apical region but they are larger in size. They measure 16-20-24 $€$ in length and 8-12-16 $€$ in width. The cells are not papillosed and not contain calcium oxalate crystals. Stomata are not observed. 


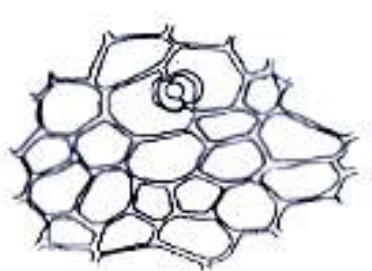

A

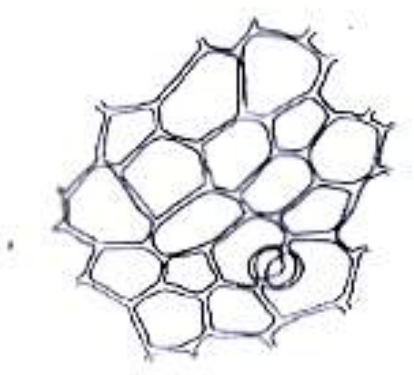

B

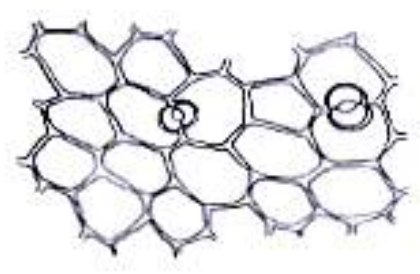

C

Fig. 19: Surface preparation of the sepal
A) Apical region of inner epidermis.
B) Middle region of inner epidermis.
C) Basal region of inner epidermis.
D) Apical region of outer epidermis.
E) Middle region of outer epidermis.
F) Basal region of the outer epidermis.

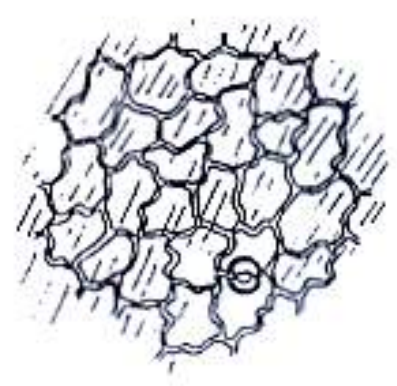

)

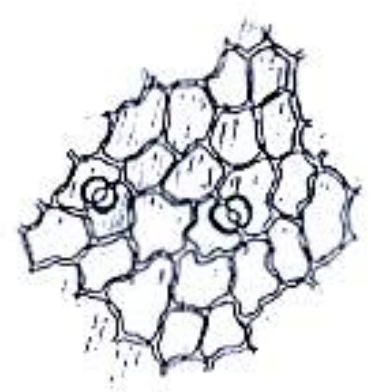

E.

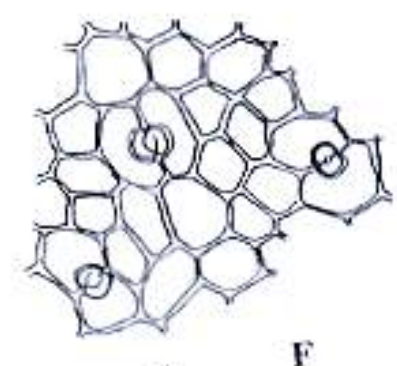

F 


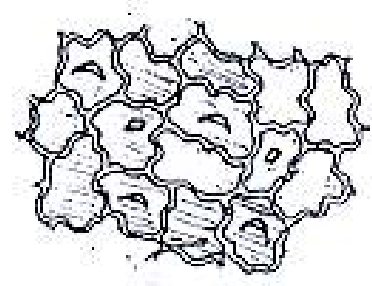

A

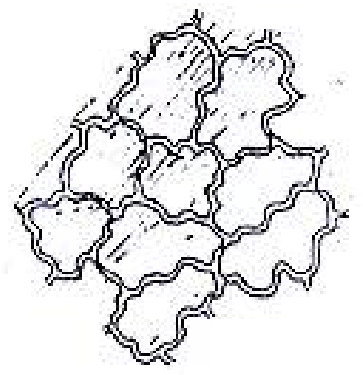

B

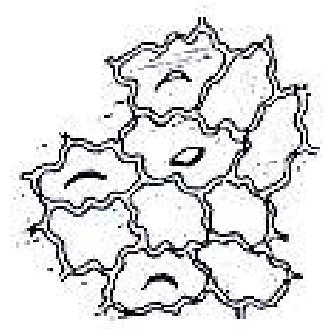

C

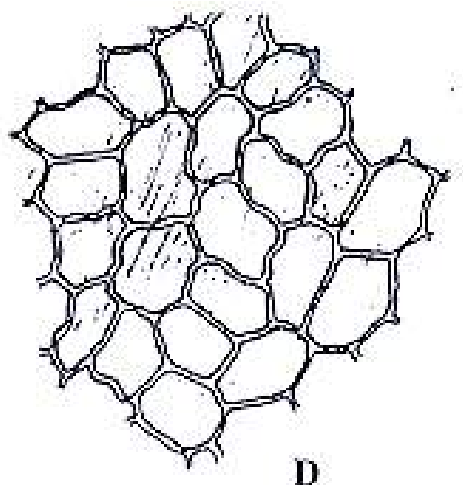

D

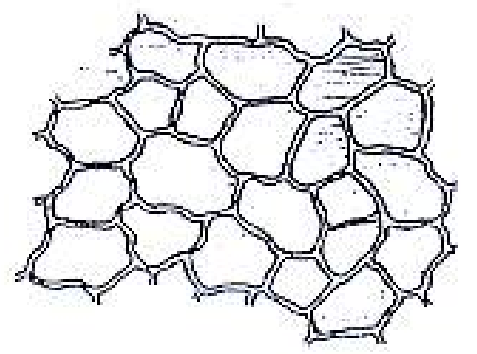

E

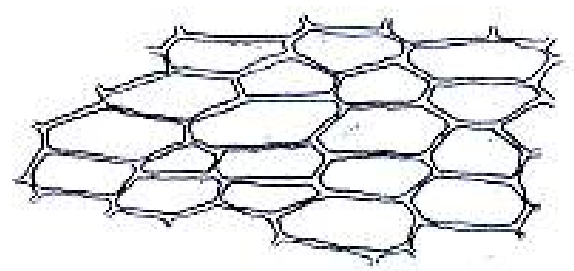

F

Fig. 20: Surface preparation of the petal

A) Apical region of outer epidermis.

B) Middle region of outer epidermis.

C) Basal region of outer epidermis.

D) Apical region of inner epidermis.

E) Middle region of inner epidermis.

F) Basal region of the inner epidermis. 
The basal region (Fig. 20C)

The cells are similar to those of the apical region but they differ in size. They measure 15-19-23 $€$ in length and 8-10-12€ in width.

\section{B- The inner epidermis}

The apical and the middle regions (Figs. 20D\&20E)

The cells in surface view are polygonal, isodiametric to slightly elongated with slightly wavy anticlinal walls covered with a striated cuticle. They measure 15-22$29 €$ in length and $10-12-14 €$ in width. Stomata are not observed.

\section{The basal region (Fig. 20F)}

The cells are similar to those of the apical and middle regions but they are more elongated and the walls are straight. They measure $12-21-30 €$ in length and 8-10-12 € in width.

\section{3- The androecium}

\section{A- The anther}

A transverse section in the anther (Figs. 21A\&22A) shows two anther lobes attached together by the connective tissue which is formed of parenchyma and through which passes a small vascular strand continuous with that of the filament. Each lobe is formed of two pollen sacs in which many pollen grains are present. The anther wall consists of an exothecium, an endothecium and a tapetum or nutritive layer.

\section{The exothecium}

The exothecium (Figs. 21B\&22B) is the epidermis of the anther wall. It is formed of one layer of square cells as seen in transverse section, but in surface view (Fig. 22C) the cells are polygonal, more or less isodiametric with straight anticlinal walls. The cells are covered with a thick striated cuticle and show papillae. They measure 10-14-18 $€$ in length and 69-12 $€$ in width. Stomata are not observed.

\section{The endothecium}

The endothecium is the hypodermis. It is formed of several layers, the outermost one is the fibrous layer but the innermost layers are of thin-walled parenchyma.

\section{The fibrous layer}

The fibrous layer (Fig. 22B) is usually formed of a single layer of lignified thick walled cells with barlike thickening. This layer is continuous around the two anther lobes except where the two pollen sacs meet. In surface view (Fig. 22D) the cells are polygonal, isodiametric and have bar-like thickening. They measure 16-20-24 $€$ in length and 813-18 $€$ in width.

\section{The tapetum}

The tapetum is formed mainly of parenchyma with nuclei and dense contents.

\section{The pollen grains}

The pollen grains (Figs. 21B\&22F) are spherical with minutely pitted exine. The mature pollen grain possesses three germ pores. It measures $9-\underline{11-13} €$ in diameter. 


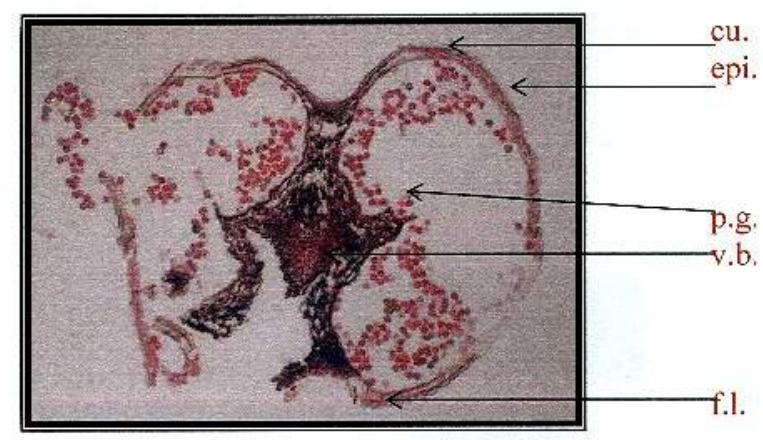

A
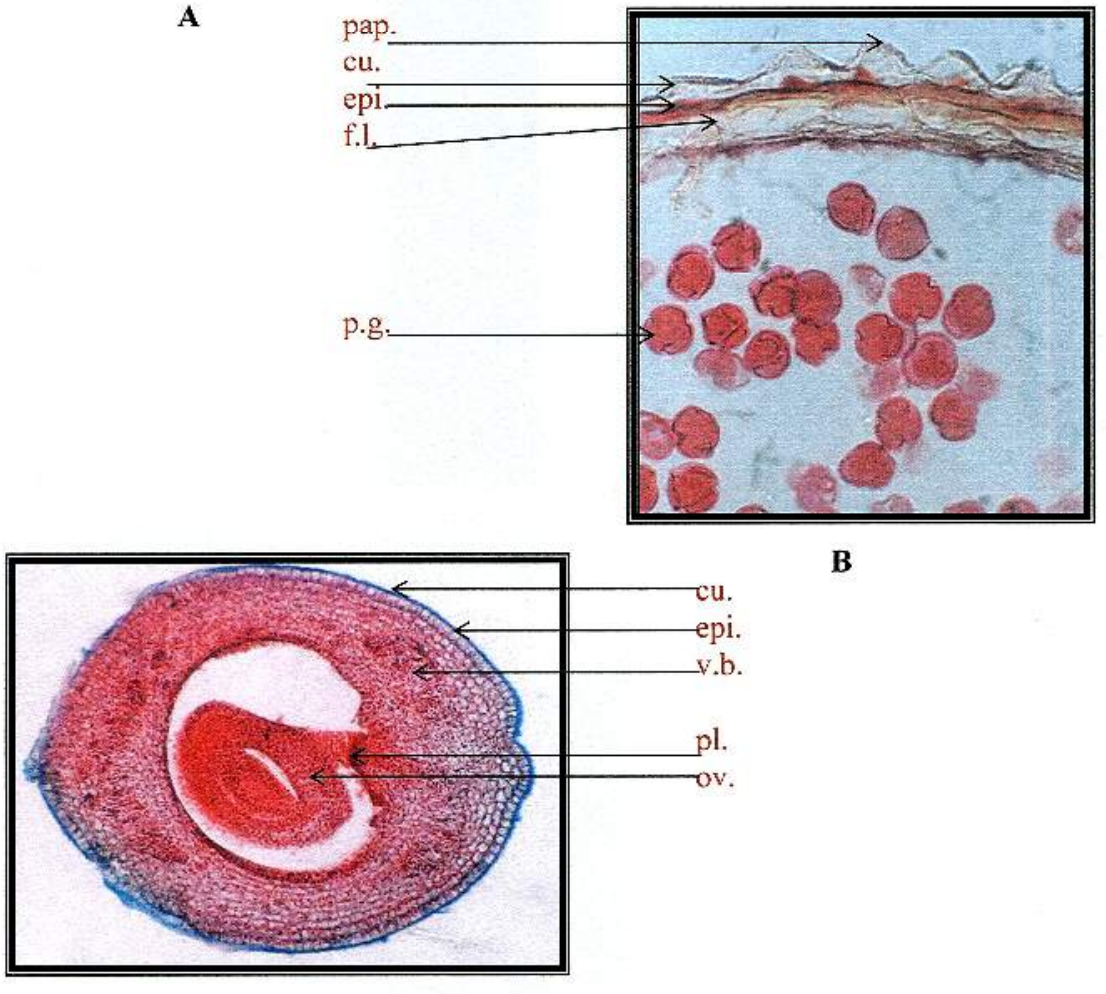

B

C

Fig. 21: A) Photo of T.S. of the anther

B) Photo of detailed T.S. of the anther

$\mathrm{x} 350$

C) Photo of T.S. of the ovary

$\mathrm{x} 150$

cu., cuticle; epi., epidermis; f.l., fibrous layer of anther; p.g., pollen grain; pap., papillae; pl., placenta; o.v., ovule; v.b., vascular bundle. 


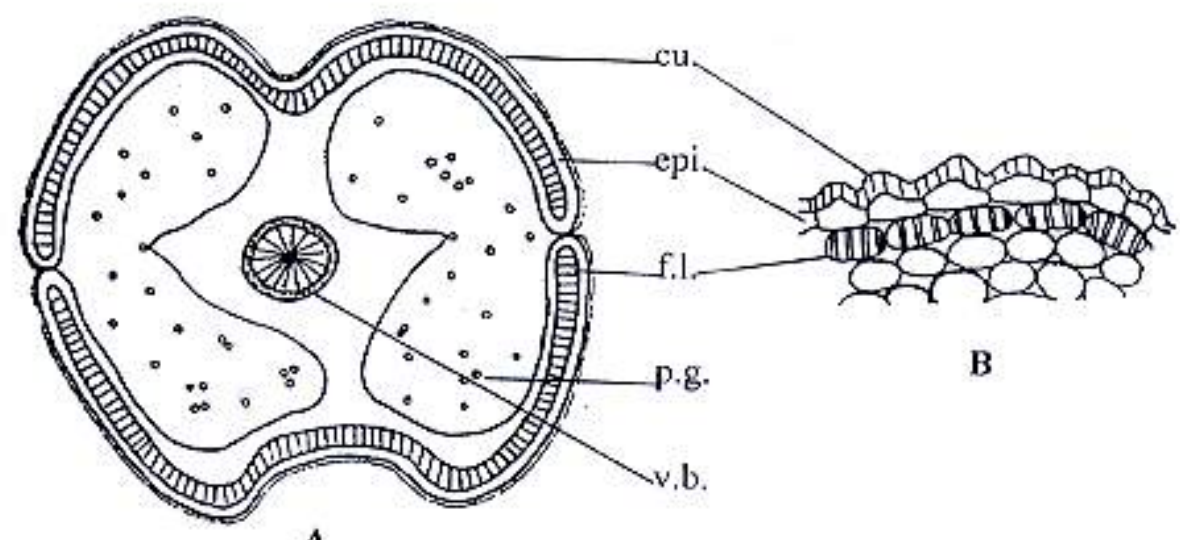

A
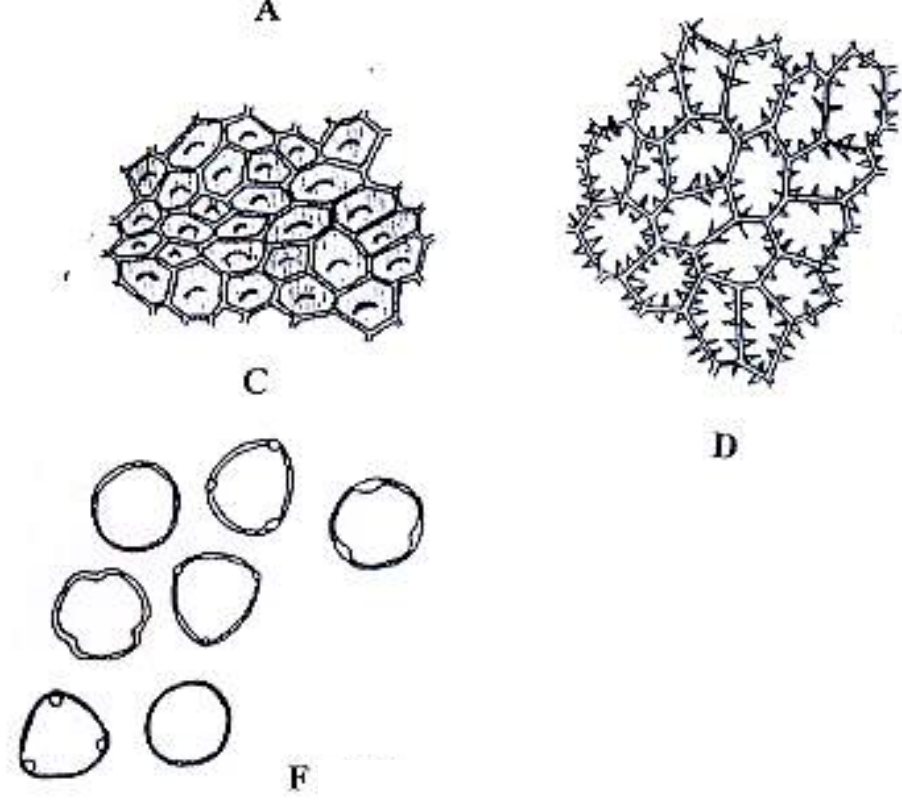

D

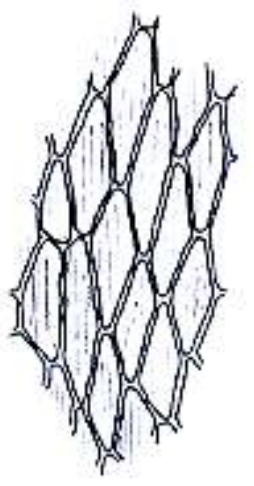

E

Fig. 22: The androecium
A) Diagrammatic T.S. of the anther
x 80
B) Detailed T.S. of the anther
x 150
C) Epidermis of the anther
$\mathrm{x} 400$
D) Fibrous layer of the anther
$\mathrm{x} 400$
E) Epidermis of the filament
$\mathrm{x} 400$
F) Pollen grains
$\mathrm{x} 450$

cu., cuticle; epi., epidermis; f.l., fibrous layer; p.g., pollen grains; v.b., vascular bundle. 


\section{B- The filament}

The filament appears in transverse section somewhat circular showing an epidermis enclosing a ground tissue of loose parenchyma and a small central vascular bundle. The epidermis of the filament in surface view (Fig. 22E) consists of polygonal, axially elongated cells with straight anticlinal walls, covered with striated cuticle, measure 22-33-44 $€$ in length and $6-8-10 €$ in width.

\section{4- The gynoecium}

\section{A- The ovary}

A transverse section in the ovary (Figs. 21C\&23A) is nearly oval in outline. It shows an epidermis enclosing a wide ground tissue of parenchyma containing cluster crystals of calcium oxalate and traversed by five collateral vascular bundles. The ovary is usually unilocular; the locule appears in transverse section to be somewhat ovoid with the ovules to the marginal placenta. The epidermis of the ovary (Fig. 23B) is formed of polygonal, isodiametric cells with straight anticlinal walls, covered with striated cuticle. They measure $10-15-20 €$ in length and 6-9-12 $€$ in width. Stomata and hairs are not observed.

\section{B- The style}

The epidermis of the style (Fig. $23 \mathrm{C}$ ) is formed of polygonal, axially elongated cells with straight anticlinal walls, covered with striated cuticle. They measure 18-26-34 $€$ in length and 8-11-14 € in width. Stomata and hairs are not observed.

\section{II) Micromorphology of the peduncle}

A transverse section through the peduncle (Figs. 24A\&25A) is nearly rounded in outline. It has an outer epidermis surrounding a cortical tissue, which consists of an outer collenchymatous layer and an inner parenchymatous one. The innermost layer of the cortex, the endodermis is distinguishable and contains starch granules. The vascular system is surrounded by a complete ring of pericyclic fibers of about 6-8 rows. The phloem is formed of soft cellulosic elements. The xylem region is radiating and usually protruding in the pith. It is formed of lignified vessels, lignified wood parenchyma and uni- or bi- seriate medullary rays. The phloem and xylem are separated by a cambial zone of 3-4 rows. The central pith is wide and parenchymatous, it contains prisms and cluster crystals of calcium oxalate as well as few minute starch granules.

\section{The epidermis}

The epidermis of the peduncle (Figs. 24B\&25C) is formed of one row of sub-rectangular to square cells as seen in transverse section while in surface view (Fig. 25B) the cells appear polygonal, somewhat axially elongated with a straight anticlinal walls covered with striated cuticle. They measure 16-22-28 $€$ in length, $12-16-20 €$ in width and $12-14-16 €$ in height. Stomata of paracytic type are rarely present. Hairs are absent. 


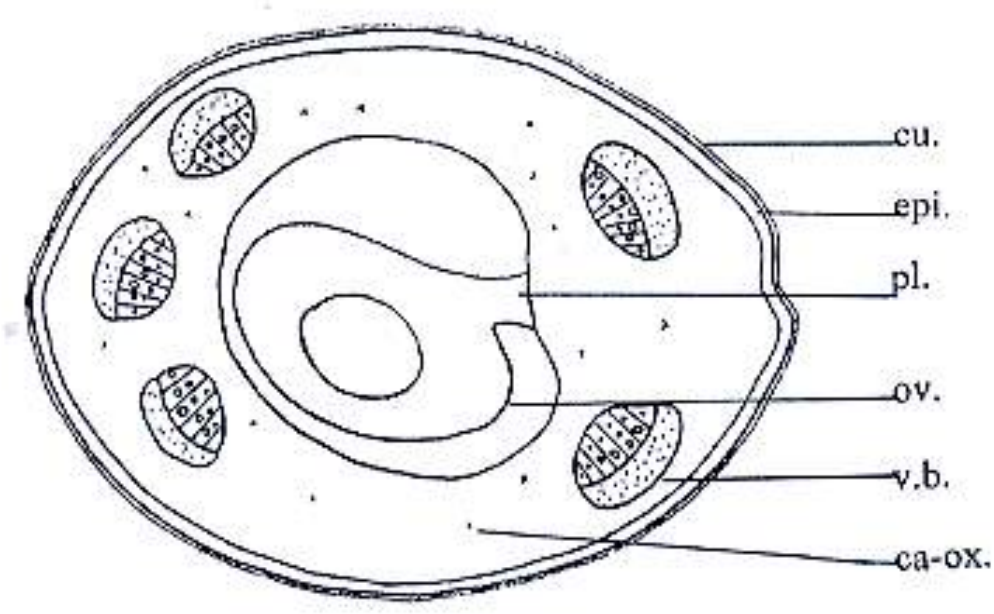

A

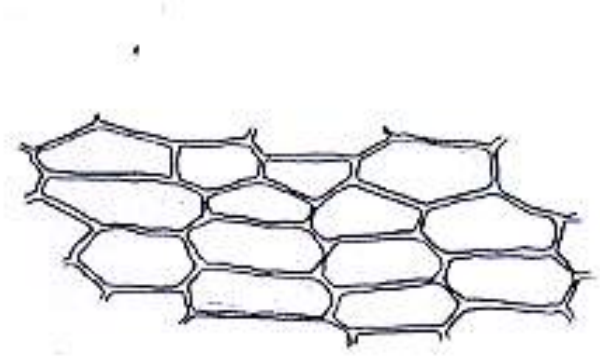

B

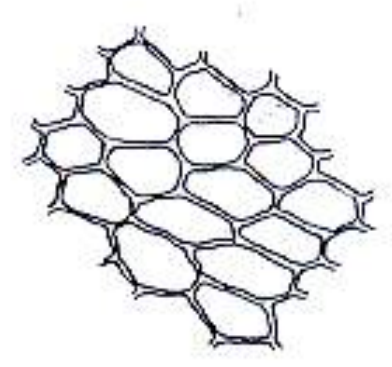

C

Fig. 23: The gynoecium
A) Diagrammatic T.S. of the ovary
x 200
B) Epidermis of the ovary
x 500
C) Epidermis of the style
x 500

ca-ox., calcium oxalate; cu., cuticle; epi., epidermis; ov., ovule; pl., placenta; v.b., vascular bundle. 


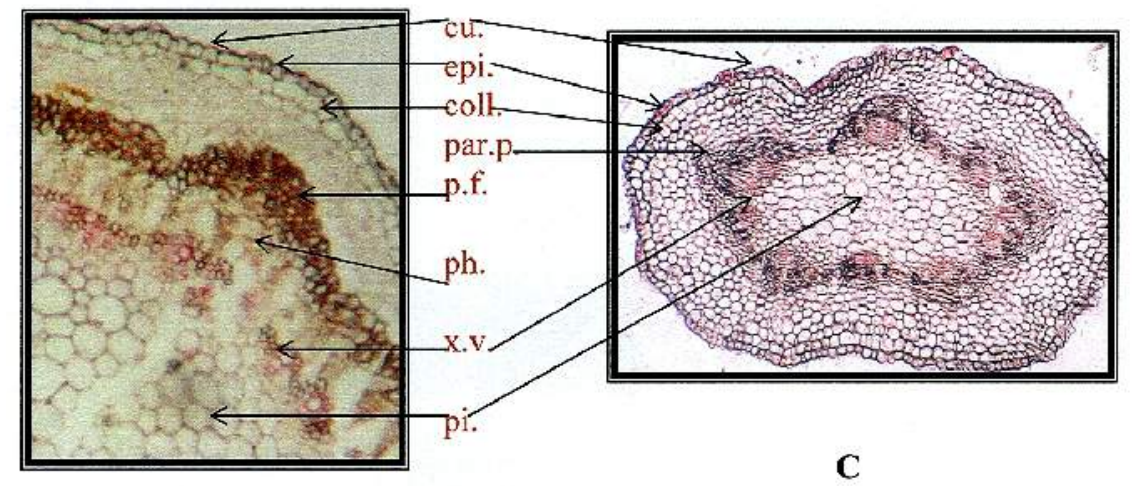

A
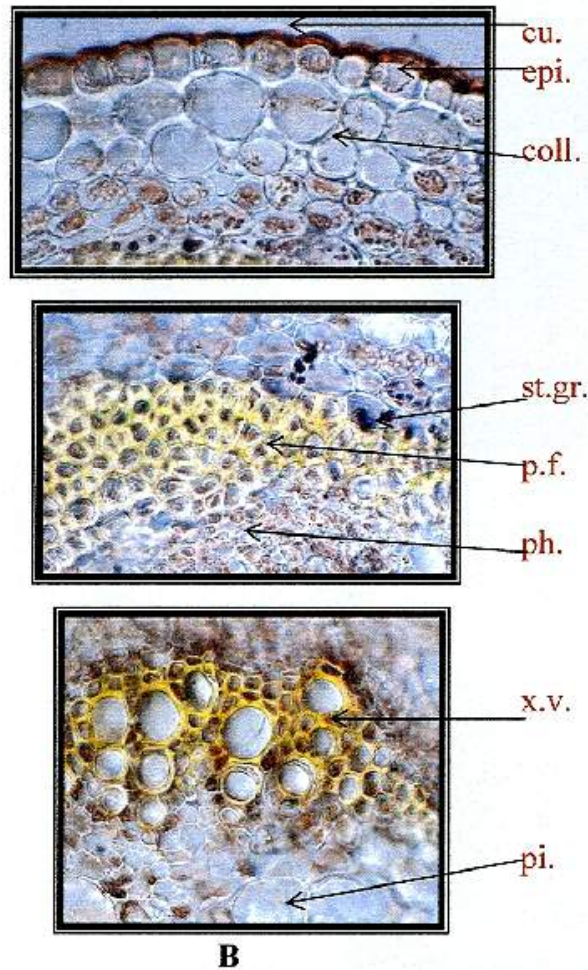

Fig. 24: A) Photo of T.S. of the peduncle

$\mathrm{x} 100$

B) Photo of detailed T.S. of the peduncle

$\mathrm{x} 500$

C) Photo of T.S. of the pedicel

$\mathrm{x} 100$

coll., collenchyma; cu., cuticle; epi., epidermis; p.f., pericyclic fiber; par.p., parenchymatous pericycle; ph., phloem; pi., pith; st.gr., starch granules; x.v., xylem vessel. 


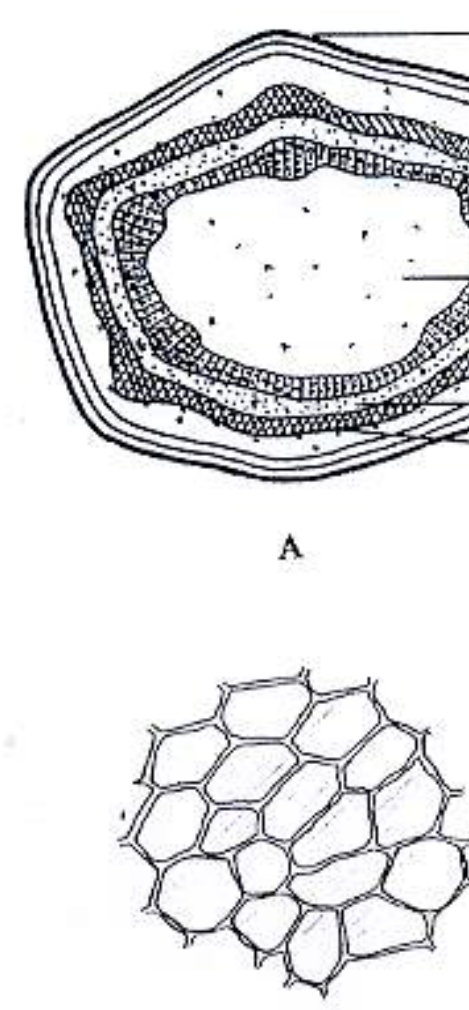

B

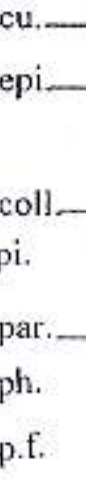

p.f.

$\mathrm{ca}-\mathrm{ox}$
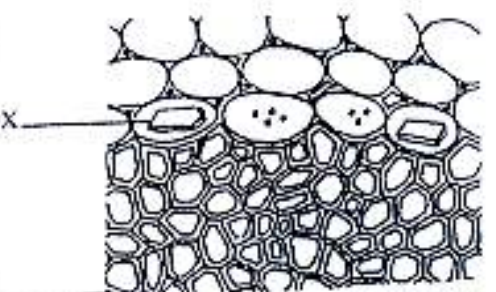

p.f.

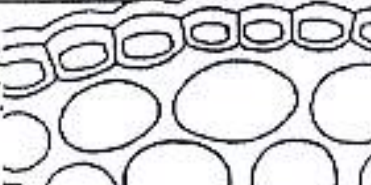

cascos

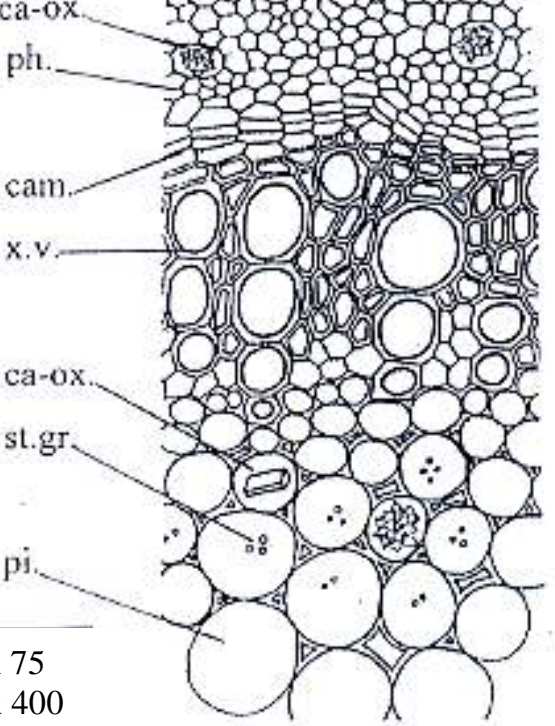

C

ca-ox., calcium oxalate; cam., cambium; coll., collenchyma; cu., cuticle; epi., epidermis; p.f., pericyclic fiber; par., parenchyma; ph., phloem; pi., pith; x.v., xylem vessel. 
The cortical tissue (Figs. 24B \&25C)

The outer collenchymatous layer consists of 1-2 rows of rounded or oval cells. The inner parenchymatous layer consists of 3-5 rows of thin walled cells having intercellular spaces. These cells contain prismatic and cluster crystals of calcium oxalate as well as few minute starch granules.

\section{The vascular system (Figs.} 24B\&25C)

The phloem is formed of sieve tubes, companion cells and phloem parenchyma. The xylem arc consists mainly of lignified spiral and scalariform vessels, measuring 5$\underline{10.5}-16 €$ in diameter. The wood parenchyma are lignified subrectangular cells. The medullary rays are formed of thin-walled radially elongated cells. The pericyclic fiber has a wide lumen, a lignified wall and an acute to acuminate apex. It measures $300-350-400 €$ in length and 3-5-7 $€$ in diameter. The parenchyma of pith are large, nonlignified and thin-walled. These cells contain prismatic and cluster crystals of calcium oxalate as well as few minute starch granules are present.

\section{III) Micromorphology of the pedicel}

A transverse section through the pedicel (Figs. 24C\&26A) is irregular in outline. It has an outer epidermis surrounding a cortical tissue, which consists of an outer collenchymatous layer and an inner parenchymatous one. The innermost layer of the cortex, the endodermis is distinguishable. The vascular system is formed of several separate collateral vascular bundles surrounded by pericycle which consists of several layers of parenchyma.The phloem is formed of soft cellulosic elements. The xylem region is radiating and formed of lignified vessels, non-lignified wood parenchyma and uni- or bi- seriate medullary rays. The central pith is wide and parenchymatous. It contains prisms and cluster crystals of calcium oxalate as well as few minute starch granules.

\section{The powdered inflorescence}

The powdered inflorescence is yellowish-brown in colour with a characteristic odour and a bitter taste. Microscopically, the powder is characterized by the following features (Fig. 27).

1- Fragments of the outer epidermis of the calyx. The cells are polygonal, isodiametric with wavy or some times straight anticlinal walls covered with a striated cuticle. Stomata of paracytic type are numerous.

2- Fragments of the inner epidermis of the calyx. The cells are polygonal, isodiametric to slightly elongated with straight anticlinal walls covered with a striated cuticle. Stomata of paracytic type are present.

3- Fragments of the outer epidermis of the corolla.The cells are polygonal, isodiametric to slightly elongated with wavy anticlinal walls. They are papillosed and covered with a striated cuticle. 


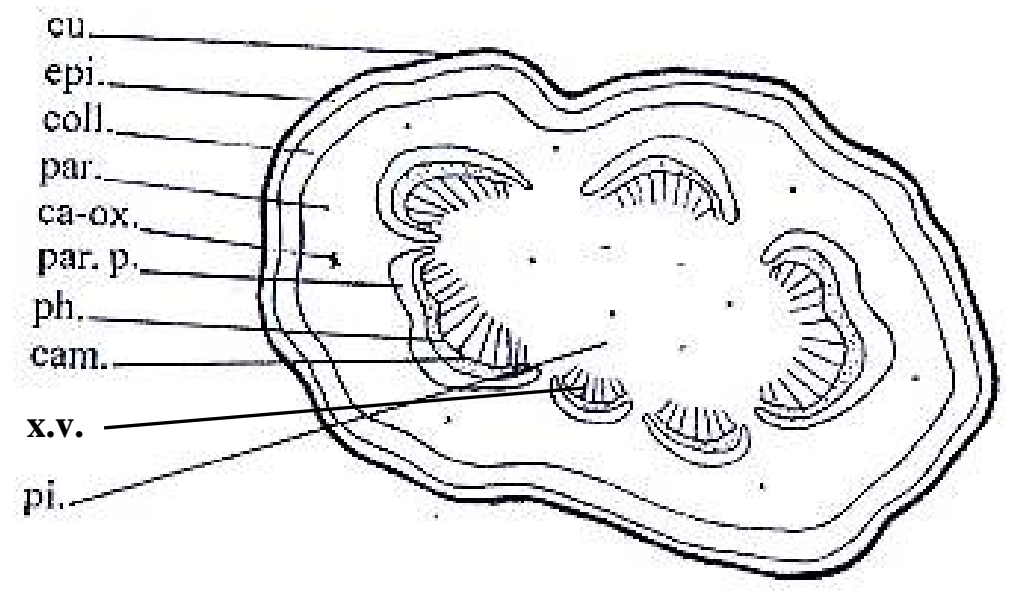

A

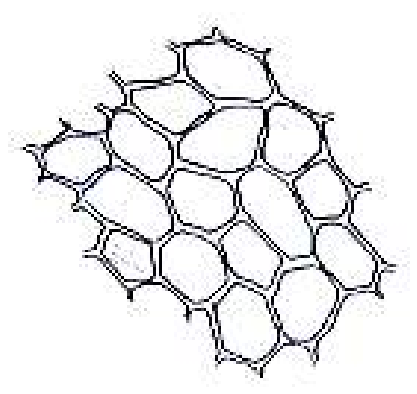

B

Fig. 26: A) Diagrammatic T.S. of the pedicel

B) Surface preparation of the pedicel

$\mathrm{x} 170$

x 600

ca-ox., calcium oxalate; cam., cambium; coll., collenchyma; cu., cuticle; epi., epidermis; par.p., parenchymatoux pericycle; par., parenchyma; ph., phloem; pi., pith; x.v., xylem vessel. 


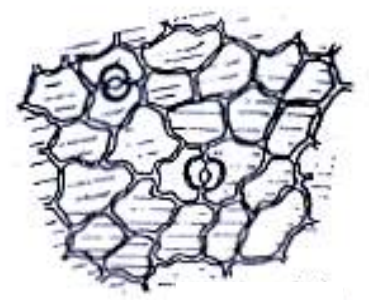

A $\times 480$

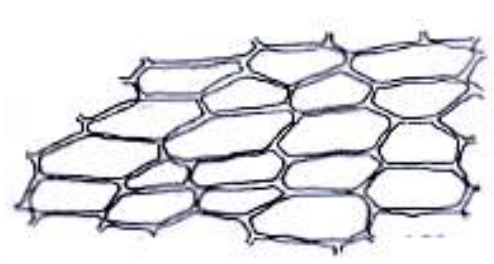

D x 480

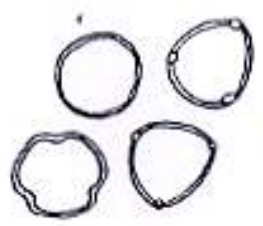

G x 390

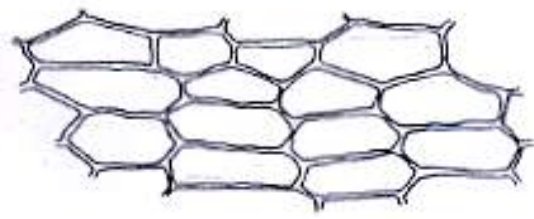

J x 480

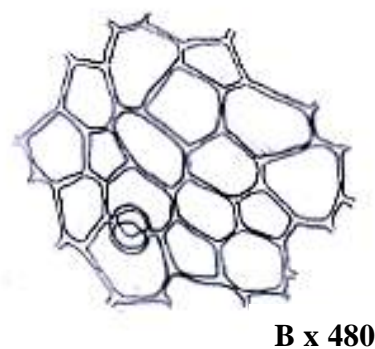

B x 480

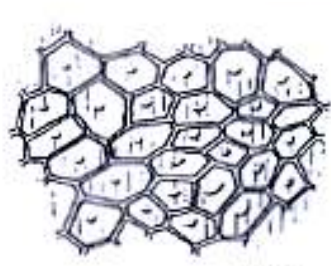

E x 390

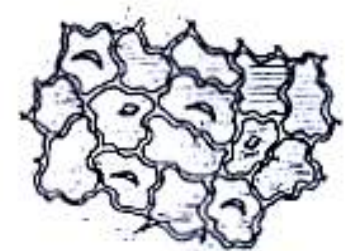

C x 480

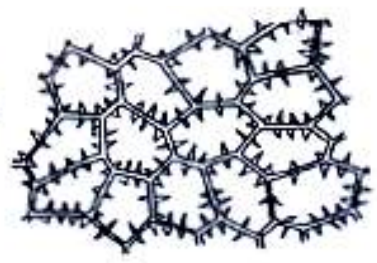

F $\times 390$

Fig. 27: Isolated elements of the inflorescence
A) Outer epidermis of calyx
B) Inner epidermis of calyx
C) Outer epidermis of corolla
D) Inner epidermis of corolla
E) Epidermis of anther
F) Fibrous latyer of anther
G) Pollen grain

H) Epidermis of filament

I) Epidermis of ovary

J) Epidermis of style

K) Xylem vessel

L) Epidermis of pedicel

M) Calcium oxalate

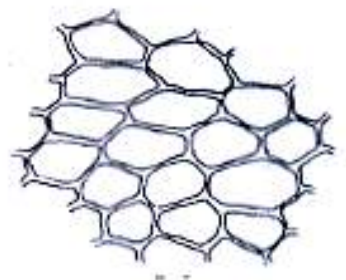

$x 480$ 
4- Fragments of the inner epidermis of the corolla. The cells are polygonal, isodiametric to slightly elongated with straight anticlinal walls covered with a striated cuticle.

5- Fragments of the epidermal cells of the anther.The cells are polygonal, more or less isodiametric with straight anticlinal walls. The cells are papillosed and covered with a thick striated cuticle.

6- Fragments of the fibrous layer of the anther. The cells are polygonal, isodiametric with lignified walls and a bar-like thickening.

7- Numerous spherical or subspherical pollen grains with a minutely pitted exine. Each one possesses three germ pores and three germinal furrows.

8- Fragments of the epidermal cells of the filament. The cells are of polygonal, axially elongated cells with straight anticlinal walls, covered with a striated cuticle.

9- Fragments of the epidermal cells of the ovary. The cells are polygonal, isodiametric cells with straight anticlinal walls, covered with a striated cuticle.

10- Fragments of the epidermal cells of the style. The cells are polygonal, axially elongated cells with straight anticlinal walls, covered with a striated cuticle.

11- Fragments of the epidermal cells of the pedicel. The cells are polygonal, isodiametric to slightly elongated with straight anticlinal walls and covered with a striated cuticle.

12- Lignified spiral and sclariform xylem vessels.

13- Scattered prisms and cluster crystals of calcium oxalate.

\section{REFERENCES}

1- L. H. Bailey, "Manual of Cultivated Plants", The Macmillan Company, New York, $6^{\text {th }}$ printing, 1961, pp. $586-87$.

2- L. H. Bailey and E. Z. Bailey, "Hortus Second", The Macmillan Company, New York, $12^{\text {th }}$ printing, 1963, pp. 146.

3- F. J. Chittenden, "Dictionary of Gardening", The Clarendon Press, Oxford, Vol. I, 1956, pp. 406-407.

4- http://davesgarden.com/trading/ tl/FLSuncoast/viewentry/21175/.

5- http://msucares.com/lawn/ garden/msgardens/03/031110.ht $\mathrm{ml}$.

6- http://edis.ifas.ufl.edu/ BODY_ST126.

7- http://www.ars-grin.gov/cgibin/npgs/html/taxon.pl?100056.

8- http://image.fs.uidaho.edu/ vide/famly076.htm.

9- L. M. Perry and J. Metzger "Medicinal Plants of East and Southeast Asia", The MIT press, Cambridge, Massachusetts, London, 1980, pp. 209-11.

10- J. M. Watt and M. G. BreyerBradwijk, "The Medicinal and Poisonous Plants of Southern and eastern Africa", E.\&S. Livingstone Ltd., $2^{\text {nd }}$ Ed., 1962 , pp. 566-74. 
11- K. R. Kirtikar and, B. D. Basu, "Indian Medicinal Plants", Jayyed Press, Delhi, Vol II, $2^{\text {nd }}$ Ed., 1935, pp. 854-79.

12- K. V. Rao, A. G. Damu, B. Jayaprakassam and D. Gunasekar, J. Nat. Prod., 62, 305 (1999).
13- V. S. Bolzani, A. A. L. Gunatilaka and D. G. I. Kingston, Tertahedron, 51, 5929 (1995).

14- J. Koyama, I. Morita, K. Tagahara and M. Aqil, Phytochemistry, 56, 849 (2001). 